\title{
Fracking and Risky Sexual Activity
}

\section{Authors: Scott Cunningham, Gregory DeAngelo, and Brock Smith}

(C) This manuscript version is made available under the CC-BY-NC-ND 4.0 license https:// creativecommons.org/licenses/by-nc-nd/4.0/

Cunningham, Scott, Gregory DeAngelo, and Brock Smith. "Fracking and Risky Sexual Activity." Journal of Health Economics 72 (July 2020): 102322. doi:10.1016/j.jhealeco.2020.102322.

Made available through Montana State University's ScholarWorks 


\title{
Fracking and Risky Sexual Activity*
}

Scott Cunningham

Baylor University
Gregory DeAngelo

Claremont Graduate University

Brock Smith

Montana State University

April 29, 2021

\begin{abstract}
This paper examines the impact of the U.S. fracking boom on local STI transmission rates and prostitution activity as measured by online prostitution review counts. We first document significant and robust positive effects on gonorrhea rates in fracking counties at the national level. But we find no evidence that fracking increases prostitution when using our national data, suggesting sex work may not be the principal mechanism linking fracking to gonorrhea growth. To explore mechanisms, we then focus on remote, high-fracking production areas that experienced large increases in sex ratios due to male in-migration. For this restricted sample we find enhanced gonorrhea transmission effects and moderate evidence of extensive margin effects on prostitution markets. This study highlights public health concerns relating to economic shocks and occupational conditions that alter the local demographic composition.
\end{abstract}

JEL Codes: I12, I15, Q33, Q35

\footnotetext{
*For questions or comments please contact Brock Smith at brock. smith1@montana.edu
} 


\section{Introduction}

The hydraulic fracturing (i.e. fracking) boom has resulted in incredible growth in the US energy industry. Following technological innovations in horizontal drilling, shale production began to surge in the late 2000s, and by 2012 US tight oil production had reached 2.5 million barrels of oil per day and shale gas production had reached 30 billion cubic feet per day according to the Energy Information Administration. Between 2000 and 2010 the number of natural gas wells nearly doubled from 276,000 to 510,000.

This boom has transformed local economies in certain parts of the country and significantly increased local employment and incomes (Feyrer et al., 2017; Maniloff and Mastromonaco, 2017). But the boom has also impacted several non-economic outcomes. Cascio and Narayan (2015) find increased high school dropout rates among males in fracking areas due to the higher return on unskilled labor. Kearney and Wilson (2018) find positive effects on birth rates, consistent with children being a normal good. A number of papers have found large increases in both property and violent crime rates (James and Smith, 2017; Andrews and Deza, 2018; Komarek, 2018; Street, 2019).

In this paper we examine the effects of fracking on an outcome that has received relatively little attention: risky sexual activity. We utilize sexually transmitted infections (STIs) as an outcome that is associated with risky, unprotected sexual encounters. STIs cost the American health care system an estimated $\$ 16$ billion in direct medical costs annually (Satterwhite, 2013). We estimate the causal effect of fracking booms on three bacterial STIs using a county-level semi-parametric difference-in-differences model similar to James and Smith (2017), where the treatment group is defined as any county lying over a booming shale play to exploit exogenous geographic variation. We find that fracking caused county-level gonorrhea rates to increase by 16.1 cases per 100,000 people as of 2013 (which is roughly $24 \%$ of the sample mean). We find no effect on syphilis transmission, on the other hand, suggesting that the impact was primarily rooted in changes in the heterosexual network. We also find no effect on chlamydia transmission which may be

due to the asymptomatic nature of that particular STI, which we discuss further in Section 2. 
While it is clear that the transmission of these infections is due to unprotected sexual intercourse, identifying the vectors of the spread of infections is critical for these communities. Given the remoteness of many fracking locations, the male dominance in the labor market opportunities, and the thinness of local dating markets, it is unlikely that such spread is occurring exclusively from casual sexual encounters. Indeed, as has been noted by many investigative reporters ${ }^{1}$ prostitution services have made their way into certain fracking regions.

To examine the impact of the fracking boom on the local prevalence of sex services/workers, we utilize a popular website used by clients of sex workers. This website, called The Erotic Review, has been used numerous times to better understand illicit sex markets (see Cunningham and Kendall (2011); Cunningham and Shah (2018); DeAngelo et al. (2019)) due to the site's national presence and the increased role that online reviews played in the organization of contemporary US sex markets (Cunningham and Kendall, 2016). We find heterogeneous effects of fracking on the number of reviews per capita (our proxy for commercial sex activity in a county). For our full sample, where the treated group is any county lying over a booming shale play, we do not find evidence of increased prostitution activity caused by fracking. This suggests that sex work may not be the central driving mechanism in the fracking led increase in gonorrhea. However, we do find moderate evidence of increased prostitution activity in areas where the boom was especially pronounced (described further below).

Because the fracking boom impacted communities in a myriad of ways, isolating any one mechanism of effects on risky sexual activity is difficult. Fracking booms draw males that are on average less educated (Cascio and Narayan, 2015) or more likely to have criminal backgrounds (James and Smith, 2017). Increased incomes could impact prostitution activity if prostitution is a normal good. ${ }^{2}$ But an important and plausible mechanism that we highlight in this study is changes in the local sex ratio (the ratio of males/females).

\footnotetext{
${ }^{1}$ For example, CNN's Lisa Ling aired an episode of This is Life called "Filthy Rich", which documented numerous prostitutes flocking to North Dakota. As noted in the New York Times article "An Oil Town Where Men Are Many, and Women Are Hounded", Williston's two strip clubs attract dancers from around the country. One female that works in the oil industry ultimately described the situation as "just people trying to have sex."

${ }^{2}$ Guiusta et al. (2006) notes that the demand for paid sex is higher among full time workers relative to part-time workers, although this analysis is purely correlational.
} 
The vast majority of oil and gas workers are male (IHS, 2016), and Wilson (2016) documents that migrants into fracking areas were significantly more likely to be male and unmarried. Adimora et al. (2001) and Adimora et al. (2004) note that imbalanced sex ratios can cause increased sexual concurrency. ${ }^{3}$ Edlund and Korn (2002) develop a model of prostitution that suggests imbalanced sex ratios can increase STI spread if the selected males are temporary residents. These men will shift from the marriage market towards non-procreative sex, and this may include increased demand for prostitution. Empirical evidence on how major male in-migrations impact risky sexual activity includes Mao et al. (2018) and Cunningham and Kendall (2011), though strong causal evidence for a persistent shock to sex ratios remains elusive.

James and Smith (2017) found that the fracking boom increased county-level sex ratios, but the average magnitude was quite small. However, this estimate was an average based on all 204 counties lying over a booming fracking play (the same baseline treatment group used in this study), most of which likely did not experience severe fracking labor shortages, which could make the average uninformative. We therefore attempt to identify fracking areas with pre-boom conditions that could plausibly lead to large changes in the sex ratio by way of male in-migration due to local labor shortages. We identify seven counties with a sufficiently sized city for a prostitution market to develop, and that are both nearby an especially large production boom and in a remote area. Each of these counties either are or are within commuting distance of a county that became significantly more gender-imbalanced towards males during the fracking boom. ${ }^{4}$ We run a restricted-sample difference-in-differences analysis with the treatment group limited to these counties. We find considerably larger effects on gonorrhea transmission than for the full sample. We do not find effects on total prostitution reviews per capita, but do find moderate evidence of positive extensive-margin prostitution effects, measured by whether a county has any non-zero number of reviews. Further, we generally do not find effects on these outcomes for cities that are close to highly productive fracking plays but

\footnotetext{
${ }^{3}$ Sexual concurrency is an epidemiological concept whereby a person engages in overlapping or "concurrent" sexual partnerships.

${ }^{4}$ These are counties above the 90th percentile in both the increase in sex ratio from 2005-2013 and the sex ratio level as of 2013. 131 counties meet this definition.
} 
also near other cities, or for cities that are isolated but not near fracking, suggesting that the combination of a large fracking boom and remoteness is a key causal factor. We view these results as suggestive and consistent with a sex ratio mechanism, though ultimately we still cannot fully separate sex ratios from the other mechanisms discussed above (negative selection of migrants, income effects).

This study contributes to the extensive literature on how fracking booms impact local communities. To our knowledge, only two other studies have examined STI transmission effects from fracking booms, or resource booms more generally. Komarek and Cseh (2017) find that gonorrhea transmission increases in fracking counties relative to non-fracking counties within four states lying over the Marcellus formation in the Northeast United States. Deziel et al. (2018) examines the effect of shale gas activity on STI transmission for a single state (Ohio, one of the four Marcellus states) from 2000 to 2016 using Poisson models with random effects and find increases in gonorrhea and chlamydia and no effect on syphilis.

We expand on these studies in several ways. We analyze the entire United States rather than one region. We use a less parametric specification that estimates how effects evolve over time and allows evaluation of parallel conditional pre-trends between the treatment and control groups. We further test the robustness of the estimated effects in several ways, including the restricted sample analysis described above. To our knowledge, we are the first to rigorously analyze the effects on sex work activity (as measured by online reviews) from a fracking boom or resource booms more generally. Finally, we explore how sex ratios and locational remoteness are linked to the effects on risky sexual behavior, which is of broader interest to the public health community.

The remainder of the article explains the theoretical mechanisms linking fracking with public health, the data and models used for estimation, our results and a brief discussion of the implications this study has for policy. 


\section{Sexually Transmitted Infections and Sex Work}

Sexually transmitted infections impose costs on society through reduced productivity, quality of life, health capital and increased mortality in some instances (Centers for Disease Control and Prevention, 2017). Several bacterial STIs have been increasing recently, suggesting a new phase in public health after a lengthy period of several decades at low levels of prevalence. In 2017, there were 555,608 documented cases of gonorrhea in the United States, which was 18.5\% higher than 2016. Even rarer STIs, such as syphilis, have reached 30,644 cases in 2017, which was a 10\% increase over 2016 cases. While bacterial STIs have less severe consequences than viral STIs (e.g. HIV) due to the efficacy of affordable treatments, treatment resistant STIs have become more common. Additionally, bacterial STIs have external harms in that they can increase the per-act probability of transmission for infections like HIV (Oster, 2005).

A mechanism by which sex workers can amplify the spread of STIs in a population is through their concurrent sexual partnerships. ${ }^{5}$ Consider a man who forms a new sexual partnership each month for one year, but each month he is monogamous to that partner. If his twelfth partner infected him with an STI, it could not cause him to infect the first eleven because he is no longer in a sexual relationship with any of them. Contrast that with a concurrent version of the same scenario in which the man has the same twelve partners each month for a year. The potential for an epidemic is much higher under concurrency than serial monogamy because of concurrency's structuring of the sexual network. Holding constant the number of partners, concurrency can amplify an STI epidemic by decreasing the average distance between infected and non-infected individuals (Morris and Kretzschmar, 1995, 1997). As a result, concurrency has a multiplier effect on an infection's growth rate and even small changes in the share of concurrent relationships can amplify an epidemic. ${ }^{6}$ Given the average sex worker is estimated to see 200-300 clients per year (National Institutes of Health, 2001), and assuming some of these are repeat clients, then greater dependency on sex workers in a sexual network may have

\footnotetext{
${ }^{5}$ Other basic mechanisms include higher risk taking activities with partners, such as unprotected sex.

${ }^{6}$ Some models show that when half of all partners in a network are concurrent, the size of the epidemic after 5 years is 10 times larger than if the same relationships had been sequentially monogamous (Morris and Kretzschmar, 1995, 1997).
} 
significant implications for understanding disease transmission. ${ }^{7}$

There are theoretical reasons to link sex workers to fracking areas. Edlund and Korn (2002) note that when there is an increase in non-residential men in an area, there is an increase in the relative demand for non-procreative sex compared to marriage. Empirical support for this hypothesis is shown in Cunningham and Kendall (2011), who found that on the days when political conventions operated in American cities during the 2008 Presidential campaign, the number of sex worker advertisements placed at Craigslist's erotic services rose relative to control cities for the duration of the campaign. This effect, termed the "men-in-transit hypothesis", has relevance in the case of fracking because, as noted above, the booms increased employment both locally and drew non-residential labor into the economy. ${ }^{8}$ For these reasons, sex workers are an important population to study when trying to understand the potential source of STI transmission. ${ }^{9}$

\section{Data}

This study uses two main data sources: county-level counts of three separate bacterial sexually transmitted infections from the Centers for Disease Control and Prevention (CDC), and reviews of sex workers from a popular national website called The Erotic Review (TER). We describe each of these data sources, as well as the benefits and shortcomings to using these data in the following subsections.

\footnotetext{
${ }^{7} \mathrm{An}$ increase in the number of sexually active people in a network can theoretically slow or even reduce the spread of STIs across a population if the marginal entrant has lower than average number of partners in the group of infected nodes (Kremer, 1996; Kremer and Morcom, 1998). Cunningham and Shah (2018) found that the decriminalization of sex work in Rhode Island from 2003-2009 reduced female gonorrhea incidence by $40 \%$. Analysis of sex worker reviews at a popular website showed that the marginal sex worker after decriminalization was drawn from a population with lower background STI risk profiles, and the type of work provided tended to have lower STI risks overall. Decriminalization may increase sex work without increasing STIs which may not be true for other shocks.

${ }^{8}$ Our empirical setting differs from Cunningham and Kendall (2011) in important ways. First, we are studying a far more persistent shock than political conventions. Second, the fracking boom likely tended to draw males of different socioeconomic status than political conventions, possibly more prone to criminal activity. Third, there may be differences in how prostitution markets operate in the more remote locations we study.

${ }^{9}$ This phenomena can be observed in observational data as well. Street prostitution for instance exhibits statistically higher levels of gonorrhea than the general population (Willcox, 1962; Dunlop et al., 1971; Potterat et al., 1979), but this has been found to be lower in instances of decriminalization of prostitution (Cunningham and Shah, 2018), which suggests sex work policy can be effective at dampening an epidemic to some degree.
} 


\subsection{Sexually Transmitted infection Data}

The CDC has collected information from state health agencies on bacterial STI incidence in the US disaggregated by race, age, gender and state since $1981 .{ }^{10}$ Unfortunately, the CDC does not distribute county level disaggregated data by demographics. The CDC only provides total counts of STIs by county which renders us incapable of determining whether our effect is being driven by specific age groups, individuals of a specific race or gender for our county-level analysis. However, in Section 5.1.3 we do use state-level analysis to examine differences in STI effects by gender.

For this study we collect data on gonorrhea, chlamydia and syphilis. County-level STI data is available from 1995 onward, but only a small number of counties are included in the early data. Counties are gradually added thereafter but coverage is not complete until 2003. Since this is still prior to the fracking boom we begin our analysis in 2003. Further, because the share of population contracting STIs is quite low (particularly for syphilis and gonorrhea), in very low-population counties just one or two cases can cause major outlier observations in transmission rates. We therefore drop counties with a sample mean population of less than 1,000 .

While we analyze the impact of fracking on gonorrhea, syphilis and chlamydia, focusing on gonorrhea has many advantages for this type of study. First, previous studies have found that gonorrhea is more influenced by the sex worker population itself (Cunningham and Shah, 2018). Second, it is relatively symptomatic with a higher per-act probability of transmission and a short incubation period (Holmes et al., 1999). Third, these factors make its observed presence in the population closely related to immediate actions that had been taken shortly before the infection, unlike other infections, such as HIV that is both asymptomatic and progresses to AIDS after many years. In short, the longer the time to symptoms, the less one can credibly tie the infection to any one temporal shock in the local conditions.

Due to historical reasons related to the social epidemiology of the infection, syphilis is both less common and has become somewhat trapped within the men-having-sex-with-

\footnotetext{
${ }^{10}$ Washington, DC has an implausible decrease in STI transmission at the end of our sample period and is thus excluded from STI analysis.
} 
men (MSM) network (Centers for Disease Control and Prevention, 2010). Thus, if fracking is causing a rise in risky behavior within the MSM network, then syphilis would be a prime candidate for study given that it is relatively symptomatic and has short incubation spells, which enables credible linking of incidence to contemporary sexual patterns. But if that is not the case, and MSM workers are a small portion of the dynamics related to fracking booms, we may not find any effect on syphilis patterns even if there is an increase in risk-taking within the heterosexual network.

Finally, there are reasons to be skeptical of chlamydia's usefulness in this study, despite its ubiquity in the population. Chlamydia is asymptomatic, and as a result, individuals who become infected remain sexually active for a longer stretch of time than either syphilis or gonorrhea. As a consequence, chlamydia has become extremely common throughout regional networks. But its asymptomatic nature means that cases in the CDC data are severely under-counted and less likely to be tied to the contemporary period in which infection occurred (and thus less likely tied to the time when the person engaged in risky sex). Chlamydia rates have increased substantially during our sample period, but this is at least partly due to expanded use of more sensitive diagnostic tests. As these tests improved, physicians encouraged patients to get tested, and chlamydia incidence rose as more cases were discovered. This means chlamydia incidence may be more a measure of supply side factors, such as physician behavior, than contemporaneous sexual behavior itself. Thus it is arguably not a surprise that we find effects for gonorrhea (which are usually symptomatic and uncomfortable) but not chlamydia despite the latter's greater prevalence. Gonorrhea symptoms show up within days of inoculation, and thus are highly tied to contemporaneous sexual behavior.

\subsection{Online Prostitution Reviews Data}

Our measures of sex work prevalence come from an online review website called The Erotic Review. ${ }^{11}$ Similar to Yelp, TER is a review website primarily servicing the heterosexual

\footnotetext{
${ }^{11}$ We considered using prostitution arrest data, but do not since arrests are endogenous to police priorities of enforcement. Areas may have low prostitution activity due to high policing. Areas with surging prostitution may not result in more arrests, on the other hand, if local police do not prioritize arresting prostitutes. Thus we focus on reviews which are not directly a measure of police enforcement
} 
sex markets, BDSM markets and transsexual markets. The site records client reviews of a sex worker's performance, appearance and other characteristics of an experience with a sex worker. ${ }^{12}$ These sites have become extremely common in the exchange of illicit and prohibited goods and services in part because they facilitate the enforcement of contracts when courts and law enforcement are not available to market participants (Cunningham and Kendall, 2016).

Data from TER were accessed from 1998-2018, but we narrow our sample period to 2003-2015 to align it with our analysis of STIs. Our data are available at the review level, meaning that we have information specific to each individual exchange of services for which a client reviewed a service provider. For each review we obtain the date and location of the service. To identify the location, we built an extractor that identifies cities within the free-text that the reviewer provides regarding where the services were performed. In $39 \%$ of the reviews the location of the service is easily obtained from the free-text information provided in the client's review (e.g. Midtown Manhattan). However, in other instances the location is difficult to identify from the client's review since the location is not easily associated with a geographic location (e.g. My car, Motel 6, etc.). When this occurs, we typically default to assigning the city that the provider lists in their profile. ${ }^{1314}$ Once choices.

${ }^{12}$ Logan and Shah (2013) analyze a review website that primarily services the MSM sex markets called Rentboy. But unlike TER, the number of observations that can be harvested from Rentboy is too small for our county level analysis.

${ }^{13}$ While the decision to utilize the city that is listed in the provider's profile could lead to mis-attribution of reviews to a particular location, we have taken several steps to ensure that this is not the case. First, if a provider has multiple reviews, we examine the location associated with other reviews for the service provider. If nearly all reviews are listed in a single location, we feel greater confidence attaching the review with a difficult to discern location to the location that is most prominent. Second, when a location is difficult to identify and the provider has multiple locations where they have provided services, we look at the most recent identifiable location and attach this location to the difficult to identify location.

${ }^{14}$ The percentage of assigned locations varies quite widely by county without a clear pattern. We regressed percentage of assigned locations for reviews over the entire 2003-2015 sample period on several county traits as of 2003 with the results displayed in Appendix Table A.1. Note that this is a crosssectional analysis, and only includes counties with at least one review. We find no effect for Gonorrhea rate, sex ratio, or population but do find significant effects for income per capita and treatment assignment. Specifically, treatment location reviews are approximately 7.1 percentage points more likely to be assigned. While this might initially be concerning, this is likely not biasing our main results, since these results are cross-sectional and do not appear to vary over time. The first graph of Figure A.1 shows the year-by-year coefficient estimates of the likelihood that location is assigned as the dependent variable using our main specification shown in Equation 1 (see Section 4). The estimated effects do not show any trend and are also not statistically different from the reference year 2003, indicating that the likelihood a location is assigned does not vary over time. The second graph of Figure A.1 shows similarly trendless 
a city is assigned to each review, we sum the number of reviews within each county to create a county-by-year panel that is used to estimate Equation (1) below. ${ }^{15}$

While these data offer a unique window into an illicit market, they have some limitations. First, despite its size and breadth, it is important to note the intent of the site. TER is a collection of reviews of sex services, provided by the clients. These reviews are not representative either of the sex workers working in an area or the clients purchasing sex services in the area, although the number of reviews on TER have grown over time. Thus, they suffer from convenience sampling properties - a complaint seen in other criticisms of data sets on illicit markets, such as the DEA's database of drug purchases (Horowitz, 2001). Despite these limitations, these data are still the best and oftentimes only way to capture any insight into the dynamics of the illicit market for commercial sex because surveys are underpowered or not fielded at all. Given that commercial sex work is illegal, there is no administrative data source of employment, sales, quality, etc. We therefore believe that these data, while imperfect, are the best that researchers have to study sex services markets. Finally, sex reviews have been shown to be an important part of the sex services market that both clients and providers utilize when making choices about engaging in illicit transactions.

\subsection{Summary Statistics}

Appendix Table A.2 presents summary statistics. In addition to statistics for the full sample, we calculated statistics separately for the treatment and control groups as of 2003 to provide pre-boom baselines. STI rates, reviews per capita, income, population, and the sex ratio are similar across the control and treatment groups in our base year (2003). However, the control group does begin at a higher average level of all three STIs in this study, which indicates the importance of our difference-in-differences design.

results when we examine our restricted sample (see Section 5.2). Lastly, for our restricted sample the assignment of locations is not relevant for the extensive margin results (which is the only case where we find evidence of prostitution effects-see Figure 8) since for our restricted sample treatment counties the location assignment percentage is never $100 \%$.

${ }^{15}$ Because Alaska and Virginia have unconventional county structures and/or names, reviews are not properly assigned at the county level in these states and we exclude them from the sample when analyzing TER reviews. 


\section{Empirical Specification}

We estimate the impact of the fracking boom on STI transmission and other outcomes using a semi-parametric model in which the treatment effect is allowed to vary by year. We prefer this to a traditional pre vs. post difference-in-differences model as it is more informative about how effects evolve over time, and also due to the lack of a clear-cut treatment date. Modern fracking with horizontal drilling techniques began as early as 1998 in Western Texas, but only gradually scaled up and spread to other areas over the subsequent 10-15 years (James and Smith, 2017). Individual fracking plays likewise typically display a gradual ramping-up of production. Our semi-parametric specification shows how outcome effects evolve over time without a necessarily arbitrary pre-post cutoff.

We estimate the following specification:

$$
Y_{i t}=\alpha+\sum_{s=2003}^{2015} \beta_{s}\left(\lambda_{s} T_{i}\right)+X_{i t}+\mu_{i}+\gamma_{t}+\epsilon_{i, t}
$$

where $Y_{i t}$ is the outcome of interest for county $i$ in year $t, \mu_{i}$ represents county fixed effects and $\gamma_{t}$ represents year fixed effects. $\lambda_{s}$ is a year indicator equal to one if $s=t$ and zero otherwise, and $T_{i}$ is an indicator equal to one if county $i$ is lying over a "booming" shale play and zero otherwise. $\beta_{s}$ is then the conditional difference between treatment and control counties in year $s$, relative to the difference in the omitted year 2003. We interpret this as the estimated treatment effect in year $s$. Standard errors for all regressions are clustered at the county level. ${ }^{16}$

As in James and Smith (2017), we define a play as "booming" if it contributed at least $1 \%$ of the increase in US shale oil or gas production between 2000-2012. Ten plays meet this threshold, ${ }^{17}$ and collectively make up more than $90 \%$ of the growth in both shale oil and gas. A map of shale plays, with booming plays indicated by dashed lines, is presented

\footnotetext{
${ }^{16}$ Results are qualitatively robust to clustering at the state level. These results are available upon request.

${ }^{17}$ These plays are the Bakken, Barnett, Bone Spring, Eagle Ford, Fayetteville, Haynesville, Marcellus, Niobrara, Spaberry, and Woodford.
} 
in Appendix Figure A.2. ${ }^{18}$ A county is assigned to the treatment group if its geographic center lies over one of these plays. This includes 203 counties in our full sample.

\section{Results}

We first examine the effects of the fracking boom on STI transmission and prostitution reviews using data from the entire nation. We analyze effects on counties lying directly over booming shale plays, and also explore geographic spillover effects, the latter of which have been found for economic outcomes (Feyrer et al., 2017; James and Smith, 2018). We then estimate effects for a restricted sample in which the treatment group is counties containing cities that are isolated and near large fracking booms.

\subsection{Full Sample Results}

\subsubsection{STI Transmission Rates}

Figure 1 presents the full-sample results when estimating Equation (1) for each of the three STI rates. For gonorrhea, effects are flat in the pre-boom period until rising significantly in the late 2000s, peaking in 2013 at roughly 16 extra cases per 100,000 people (compared to a sample mean of about 67). The mild decline in 2014 and 2015 corresponds to the crash in oil prices and decline in fracking employment. For chlamydia, there is a downward trend at the start of the sample period and a fairly sharp increase starting in 2012 (note that chlamydia is much more common with a sample mean of 293 cases per 100,000). While this increase is suggestive, the difference relative to 2003 is not statistically significant and we do not make strong conclusions about chlamydia effects.

Francis (2008) finds evidence of shifts between heterosexual and MSM behavior when the costs of the latter rose due to HIV risks. Similar effects could occur when women are scarce (Posner, 1992). But we do not find evidence for this in that we find no effects on syphilis transmission. As discussed in Section 3.1, Gonorrhea has a higher per-act probability of transmission than syphilis, and over time the former has spread more deeply into heterosexual networks. But syphilis has been, through historic accident, trapped

\footnotetext{
${ }^{18}$ This figure also appears in James and Smith (2017).
} 
largely within MSM networks, and given the low rates of heterosexual sexual contact for this sub-population, syphilis has failed to "jump" beyond the MSM network's boundaries. This lack of an effect on syphilis could be a result of dominant selection of heterosexual male workers.

\subsubsection{Spillover Effects}

We next test for the presence of spatial spillover effects for gonorrhea transmission. Since fracking production often takes place in areas with sparse population, some of the activity that leads to STI transmission may occur in nearby population centers that do not lie directly over plays. To test this we define the treatment group as any county within a state that contains a booming play (15 states in all), but exclude counties that lie directly over a play from the regression. Hence we are comparing counties that may receive within-state spillover effects from fracking counties to counties in states with no booming plays. The results shown in Figure 2 suggest significant spillover effects, with estimates of similar magnitude to the main specification in the latter part of the sample period. We alternatively test spillovers by defining the treatment group as counties that border counties over a booming play but do not lie over a booming play themselves (again excluding counties lying directly over a play from the sample). These results shown in Figure 3 display a similar pattern.

The spillover results raise the question of whether the overall effects shown in Figure 1 are mainly driven by spillovers. We next test strictly within-state treatment effects by adding state-by-year fixed effects to Equation (1), while returning to the original treatment definition of lying over a booming play. This specification thus compares differences in gonorrhea rates between counties lying over a booming play and other counties within the same state (note that because of the spillover effects we find, counties within fracking states not lying over a play are not a valid counterfactual, and this specification is only meant to find within-state differences, rather than an overall treatment effect). The results are shown in Figure 4. Effects are again flat for the first part of the sample period before beginning to rise around 2010. Given that this is a demanding specification, the standard errors are large and only the estimate for 2011 is significant at a $10 \%$ level. Still, these 
results are suggestive that while substantial within-state spillovers are present, the largest effects occur for counties lying directly over a play.

Given the evidence of spillover effects, it can be argued that counties near our treatment counties are inappropriate as controls. In Appendix Figure A.3 we estimate Equation (1) when excluding non-treatment counties within a state that includes a booming play. The effects are qualitatively similar but slightly larger as expected.

\subsubsection{Robustness of National Gonorrhea Results}

We next perform additional tests of robustness for the estimated effects on gonorrhea, which are shown in Appendix Figures A.4-A.6. First, we exclude North Dakota counties from the sample. The increase in energy production was particularly extreme in western North Dakota, which was also unusually isolated and sparsely populated. Likely due to these factors, treatment effects were very large for North Dakota (as we show in Appendix B). However, as shown in Appendix Figure A.4, North Dakota is not driving the national results as the effects are largely unchanged when excluding North Dakota counties.

As argued in James and Smith (2017), defining treatment counties as those lying over a booming play effectively yields an intent-to-treat effect, with the advantage that variation is geographic and thus convincingly exogenous, and the disadvantage that not all such counties actually experienced a shale boom, so that we may be underestimating the true treatment-on-treated. We therefore run the same specification as Equation (1) but exclude treatment counties that were below the treatment group's 25th percentile in total production resulting from new wells over the fracking boom period. Many of these counties did in fact have zero or very small new production levels. Nevertheless, the effects shown in Appendix Figure A.5 are of similar magnitude to the full sample.

James and Smith (2017) also point out that county-level population estimates may have sometimes underestimated the rapid rise in population in some boom towns, which would create bias in our estimates of per-capita effects. We therefore estimate Equation (1) using gonorrhea cases per employee as the dependent variable, rather than cases per population. County-by-year employment data were collected from the Bureau of Economic Analysis (BEA). Importantly for this analysis, these employment counts correspond to 
place-of-work, not place-of-residence, and jobs that were only worked part of the year are weighted accordingly. The results using gonorrhea cases per employee as the dependent variable are shown in Appendix Figure A.6 and are virtually unchanged.

As discussed in Section 3, county-level STI transmission rates are not available for all counties until 2003, which is the starting year in our main specification. However, we can use a subsample of counties that report STI data going back to 2000 enabling us to examine pre-trends going further back for that subset. This subsample includes 36 states, ${ }^{19}$ but only 8 of the 15 states that contain treated counties in our full sample, so the results are not readily comparable to the main specification. The results for this subsample are shown in Appendix Figure A.7. In this case there is a very mild pre-trend early in the sample with effects accelerating in 2012. The effect magnitude by 2015 is similar to the main specification despite the substantial difference in treatment group composition.

Finally, we attempt to analyze differences in effects by gender. Although we are not aware of epidemiological models that make predictions about differences in STI transmission rates by gender, any such differences could be descriptively interesting. However, the CDC only provides demographic STI infection data at the state level, not the county level. Therefore we run a state-level analysis, including state and year fixed effects, where the treatment group is defined as any state containing a booming play (15 states in all). These state-level, gender-specific results are shown in Appendix Figures A.8 and A.9. ${ }^{20}$ Estimates are similar in magnitude to the county-level analysis, though less precise due to state-level aggregation. While estimates are slightly larger for females, the male and female effects are not statistically different from each other.

\subsubsection{Prevalence of Prostitution}

We next estimate the effect of fracking on the prevalence of prostitution. Because of the inherent difficulties of assigning each review to one county (see Section 3.2), several counties end up with unrealistically large measurements of reviews per capita when incorrectly

\footnotetext{
${ }^{19}$ Before 2003, states either report STI data for all counties or none.

${ }^{20}$ Here the dependent variable is number of male (female) gonorrhea cases per 100,000 males (females).
} 
assigning reviews. We deal with this problem in a few ways. First, since low-population counties are particularly prone to inflated reviews per capita measurements, and because they are generally unlikely to have any prostitution market at all, we limit our sample to counties whose highest population observed in the sample is at least 30,000 people. ${ }^{21}$ Second, we use an alternative sample and treatment definition further based on the assumption that non-negligible prostitution markets generally only exist in medium or large cities, and any prostitution effects may only show up in cities that are nearby fracking plays, rather than necessarily lying over fracking plays. We limit this alternative sample to counties that contain a city of at least 30,000 people as of 2010 according to data compiled by the Spatial History Project at Stanford University. Then we define treatment counties as those containing a city that is closer to a county lying over a booming play than any other city (including cities that lie directly over booming plays). Finally, for both specifications we further protect against spurious outliers by excluding counties with more than two reviews per 1000 people, which is over the 99th percentile. By manual checking, the vast majority of observations over this threshold are due to incorrect location assignment. However, results are not sensitive to changing this threshold or dropping the threshold altogether.

Figures 5 and 6 present results when estimating Equation (1) using both of the methods described above. Surprisingly, for reviews per capita we find negative and statistically significant treatment effects. In both cases, by 2015 the magnitude of the negative effects is similar to the sample mean. However, in both cases there is a consistent downward linear trend throughout the sample period, so we do not interpret these estimates as causal. ${ }^{22}$ To investigate extensive-margin prostitution effects that may be obscured by examining reviews per capita, we run the same two specifications using a non-zero reviews dummy as the dependent variable. For the full sample we do not find evidence of extensive-margin effects. For the sample limited to counties containing cities, there is an increase coinciding with the fracking boom, but effects are not statistically significant. Overall we do not

\footnotetext{
${ }^{21}$ Results do not qualitatively change with different thresholds or no threshold whatsoever.

${ }^{22}$ If we run the full-sample specification controlling for county-specific linear trends, the effects over time stay close to zero and are not significant, consistent with the interpretation of pre-existing trends and no effect of fracking. These results are shown in Appendix Figure A.10, which has the same axis range as the first panel of Figure 5 to aid comparison.
} 
find evidence that the increase in STI transmission rates is being driven by increased prostitution activity at the national level.

\subsection{Restricted Treatment Group Analysis}

We do not find strong evidence of effects on prostitution activity using the full national sample of counties. However, it is theoretically plausible that prostitution is only affected under specific conditions. For example, because the national average effect of fracking booms on sex ratios is small in magnitude (James and Smith, 2017), we might not detect national prostitution effects in the case that they are caused by sex ratio imbalances, but might detect them in specific circumstances where the sex ratio does increase. Therefore we next estimate effects on STI transmission and prostitution using a restricted treatment group where conditions are such that any effects on these outcomes would theoretically be especially pronounced. We select counties that meet the following criteria: (1) is within a high-production (above the 75th percentile) fracking county or within commuting distance (60 miles) of one; (2) contains a city of at least 30,000 as of 2010, based on the assumption that non-negligible prostitution markets do not exist in strictly rural areas; (3) contains city that is not within commuting distance (60 miles) of another city (with one exception, discussed below); (4) is the only city within the high-producing county, or if there is no city within the county, then the only city within 60 miles of the county. The reasoning behind these criteria is to identify areas where there is a large male labor demand shock, and there is a single city that is likely to absorb much of the resulting in-migration and prostitution demand.

These criteria yield seven restricted treatment group counties: Minot, ND is the only city within commuting distance of the most productive parts of the Bakken play. Parkersburg, WV is near a highly productive part of the Marcellus play; Laredo, TX lies near the most productive part of the Eagle Ford play; Odessa, TX and Midland, TX both lie on a productive part of the Permian basin $;{ }^{23}$ Hobbs, NM lies further on the western end of the

\footnotetext{
${ }^{23}$ These cities are separate but quite close to each other, which technically violates our isolated city condition above, but because they are both in the middle of a productive fracking region and jointly comprise a roughly continuous band of development with no other cities nearby, they are included in this analysis.
} 
Permian basin; Casper, WY is the only city in the vicinity of the Niobrara play. These are generally smaller cities, ${ }^{24}$ and each of the counties containing these cities are or are within commuting distance of a county that experienced unusually high increases in the sex ratio. ${ }^{25}$ Further, these counties experienced substantial average sex ratio increases themselves. ${ }^{26}$ However, as discussed in Section 1, we cannot cleanly isolate sex ratios from other significant changes occurring in these regions, including large income shocks and negative selection of in-migrants. The evidence of within-state spillover effects for non-fracking counties shown in Figure 2 suggest that commuting channels or state-wide income-based mechanisms could be relevant.

We next estimate Equation (1) for our main outcomes of interest when restricting the sample to counties containing cities of at least 30,000 and using the restricted treatment group described above. We also omit all other counties lying over a booming play from the sample. These results are given in Figures 7 and 8. The results are generally similar to the full sample results, but with amplified magnitudes where there are significant effects. The major rise in gonorrhea rates begins slightly later for the restricted treatment group, but the coefficient at the 2014 peak is roughly four times larger than for the full sample. This magnitude, which is compared to a 2003 baseline, may be somewhat misleading since the restricted treatment group did experience a significant jump early in the sample period, but the difference in coefficients between 2007 and 2014 is still more than twice as large as for the full sample. There is no evidence of effects on chlamydia. Estimates for syphilis are actually negative, though this is mainly due to a negative trend early in the sample period and prior to major production booms nearby these particular counties (See Appendix Figure B.4).

For prostitution reviews per capita, we find a nearly linear downward trend throughout the sample period, similar to the full sample result. However, for the non-zero review

\footnotetext{
${ }^{24}$ Each city had less than 150,000 population as of 2010, except for Laredo which had roughly 251,000.

${ }^{25}$ These are counties above the 90th percentile in both the increase in sex ratio from 2005-2013 and the sex ratio level as of 2013, as discussed in Section 1.

${ }^{26}$ This is shown in Appendix Figure A.11, which is the result of estimating Equation (1) with sex ratio as the dependent variable and when restricting the sample to counties containing cities of at least 30,000, restricting the treated group to the seven counties given above, and dropping any other counties lying over a booming play. The effect on sex ratio starts rising gently in 2006, accelerates later in the sample, and is slightly less than .05 by 2015 , which is roughly the sample standard deviation.
} 
indicator variable we do find a positive rise with similar timing as the gonorrhea outcome. This is a qualitatively large effect, implying that non-zero review activity is $32 \%$ more likely at the end of the sample period for the restricted treatment group. This is likewise much larger than the rise around the same time for the full sample. However, given the small treatment group the effects at the end of the sample are not significant at $5 \%$ level, but are significant at a $10 \%$ level. This result, along with the synthetic control results shown in Appendix B (discussed below), suggest that prostitution markets only respond to large fracking shocks in some settings rather than all.

We next explore the importance of the individual criterion to be included in our restricted treatment group. The two key criteria are having a city within commuting distance of a high-production fracking county and being isolated. Next we define two "placebo" treatment groups as cities that meet one criteria but not the other. In Appendix Figure A.12, we show results for all main outcomes when the treatment group is defined as counties containing cities that are near high production but not isolated, and otherwise dropping treated cities from the sample. In Appendix Figure A.13, the sample consists of only non-fracking states and the treatment group is counties containing isolated cities. As with the restricted sample regressions, for both sets of results the sample only includes counties containing cities. There are generally no significant effects, with one exception being negative estimates for reviews per capita with the first placebo group, though that appears to be a pre-existing trend similar to the full treatment group. Another exception is the non-zero reviews indicator for the second placebo group, though that likewise appears to be a result of pre-existing trends. The lack of effects for either placebo group is consistent with the hypothesis that the interaction of a large production shock and geographic remoteness are key conditions for the large gonorrhea effects and extensivemargin prostitution effects observed in Figures 7 and 8.

The first placebo group (i.e. counties containing cities that are near high production, but not isolated) offers further evidence about the mechanism behind STI increases. Appendix Figure A.14 shows effects on these counties using the sex ratio and income per capita $^{27}$ as the dependent variables. There is no effect on sex ratios but a significant pos-

\footnotetext{
${ }^{27}$ County-by-year income per capita comes from the Bureau of Economic Analysis.
} 
itive effect on income. Given the overall lack of effects on STIs and prostitution for this group, this provides suggestive evidence that sex ratios are an important mechanism for these outcomes. However, the income effects for the placebo group are roughly $1 / 10$ of the income effects for the restricted sample treatment group (see Appendix Figure A.15 for the restricted sample regression result for income per capita), so we still cannot separate these especially large income shocks from large sex ratio increases.

Finally, in Appendix B we implement an alternative analysis for remote locations that experienced large fracking booms, performing several individual comparative case studies. We first analyze North Dakota at the state level, as the Bakken boom was the most extreme in terms of both production levels and remoteness, and where effects on other social outcomes like crime have been found to be the largest (James and Smith, 2017). This analysis uses both single-treatment OLS with randomization inference and synthetic controls. We then run individual synthetic controls for our seven restricted treatment group counties analyzed above. The results for both North Dakota and the county analysis are generally consistent with the restricted sample findings above of enhanced gonorrhea effects and moderate evidence of extensive-margin prostitution review effects (though not all individual case study counties experience significant effects). These procedures and results are discussed in more detail and presented in Appendix B.

\section{Conclusion \& Policy Discussion}

The fracking boom experienced in the late 2000's significantly changed the socio-economic landscape in many remote parts of the United States. In addition to economic outcomes, a growing body of research has explored the impacts of this boom on social and healthrelated outcomes such as crime and pregnancies. We contribute to this literature by analyzing the effects of the fracking boom on risky sexual activity. Our results indicate that fracking caused county-level gonorrhea rates to significantly increase, but we find no effect on syphilis, suggesting that the impact was primarily rooted in changes in the heterosexual network. Additionally, we find no effect on chlamydia likely due to its asymptomatic nature. We do not find evidence of increased prostitution activity for the 
full national sample. But when focusing on remote areas that experienced large production shocks, and were thus more likely to experience an influx of male laborers and imbalanced sex ratios, we find moderate evidence of extensive-margin prostitution effects.

This research speaks to important, but often overlooked, aspects of economic development and growth. Specifically, as new opportunities to capitalize on profits arise, the conditions that give rise to such profits merit consideration from public health and community planning professionals. Specifically, our research suggests that job opportunities that occur in remote communities can be particularly vulnerable to public health concerns. This study highlights imbalanced sex ratios as a plausible channel of increased risky sexual activity, though it is difficult to isolate any one mechanism since these communities were changed in several ways. To enhance our understanding of the mechanism that is driving the spread of STIs in scenarios such as fracking, lab-in-the-field and sociological methods could be used to determine how public health awareness campaigns (either via word of mouth or distribution of prophylactics) impact risky sexual choices in heterosexual communities that are dominated by a single gender. 


\section{References}

Abadie, Alberto, Alexis Diamond, and Jens Hainmueller, "Synthetic Control Methods for Comparative Case Studies: Estimating the Effect of California's Tobacco Control Program," Journal of the American Statistical Association, June 2010, 105 (490), 493-505.

- and Javier Gardeazabal, "The Economic Costs of Conflict: A Case Study of the Basque Country," American Economic Review, March 2003, 93 (1), 113-132.

Adimora, Adaora A., Victor J. Schoenbach, Francis E. A. Martinson, Kathryn H. Donaldson, Robert E. Fullilove, and Sevgi O. Aral, "Social Context of Sexual Relationships Among Rural African Americans," Sexually Transmitted Diseases, February 2001, 28 (2), 69-76.

_ , _, Francis Martinson, Kathyrn H. Donaldson, Tonya R. Stancil, and Robert E. Fullilove, "Concurrent Sexual Partnerships among African Americans in the Rural South," Annual Epidemiology, March 2004, 14 (3), 155-160.

Andrews, Rodney J. and Monica Deza, "Local natural resources and crime: Evidence from oil price fluctuations in Texas," Journal of Economic Behavior \& Organization, 2018, 151 (C), 123-142.

Cascio, Elizabeth U and Ayushi Narayan, "Who needs a fracking education? the educational response to low-skill biased technological change," Technical Report, National Bureau of Economic Research 2015.

Centers for Disease Control and Prevention, Syphilis and MSM - CDC fact sheet, Atlanta, GA: CDC, 2010.

_ , "Sexually Transmitted Disease Surveillance," 2017.

Cunningham, Scott and Manisha Shah, "Decriminalizing Indoor Prostitution: Implications for Sexual Violence and Public Health," Review of Economic Studies, 2018, 85 (3), 1683-1715.

— and Todd D. Kendall, "Men in Transit and Prostitution: Using Political Conventions as a Natural Experiment," The B.E. Journal of Economic Analysis and Policy, 2011, 11 (1).

_ and _, Examining the Role of Client Reviews and Reputation within Online Prostitution, Vol. Handbook on the Economics of Prostitution, Oxford University Press, 2016.

DeAngelo, G., J. Shapiro, J. Borowitz, M. Cafarella, C. Re, and G. Shiffman, "Pricing Risk in Prostitution: Evidence from Online Sex Ads," Journal of Risk and Uncertainty, 2019.

Deziel, Nicole C., Zoe Humeau, Elise G. Elliott, Joshua L. Warren, and Linda M. Niccolai, "Shale Gas Activity and Increased Rates of Sexually Transmitted Infections in Ohio: 2000-2016," PLOS One, March 23 2018, https://doi.org/10.1371/journal.pone.0194203.

Dunlop, E.M.C., Amy M. Lamb, and Dorothy M. King, "Improved tracing of contacts of heterosexual men with gonorrhea: relationship of altered female to male ratios," British Journal of Venereal Disease, 1971, 47, 192-195.

Edlund, Lena and Evelyn Korn, "A Theory of Prostitution," Journal of Political Economy, 2002, 110 (1), 181-214.

Feyrer, James, Erin T. Mansur, and Bruce Sacerdote, "Geographic Dispersion of Economic Shocks: Evidence from the Fracking Revolution," American Economic Review, April 2017, 107 (4), $1313-34$. 
Francis, Andrew, "The Economics of Sexuality: The Effect of HIV/AIDS on Sexual Behavior, Desire and Identity in the United States," Journal of Health Economics, 2008, Forthcoming.

Guiusta, Marina Della, Maria Laura Di Tommaso, and Steinar Strom, "What money buys: Clients of street sex workers in the US," Applied Economics, 2006, 41 (18), 2261-2277.

Holmes, King K., P. Frederich Sparling, Per-Anders Mardh, Stanley M. Lemon, Walter Stamm, Peter Pio, and Judith N. Wasserheit, Sexually Transmitted Diseases, 3rd ed., McGrawHill Professional, 1999.

Horowitz, Joel L., "Should the DEA's STRIDE Data Be Used for Economic Analysies of Markets for Illegal Drugs?," Journal of the American Statistical Association, 2001, 96 (456), 1254-1262.

IHS, "Minority and Female Employment in the Oil and Natural Gas and Petrochemical Industries: 2015-2035," Washington, DC: American Petroleum Institute. Retrieved September, 2016, 22, 2017.

James, Alexander and Brock Smith, "There Will be Blood: Crime Rates in Shale-Rich US Counties," Journal of Environmental Economics and Management, July 2017, 84, 125-152.

_ and _ , "The Geographic Dispersion of Economic Shocks: Evidence from the Fracking Revolution: Comment," Technical Report 2018.

Kearney, Melissa S. and Riley Wilson, "Male Earnings, Marriageable Men, and Nonmarital Fertility: Evidence from the Fracking Boom," Review of Economics and Statistics, October 2018, 100 (4), 678690.

Komarek, Tim and Attila Cseh, "Fracking and Public Health: Evidence from Gonorrhea Incidence in the Marcellus Shale Region," Journal of Public Health Policy, November 2017, 38 (4), 464-481.

Komarek, Timothy M, "Crime and natural resource booms: Evidence from unconventional natural gas production," The Annals of Regional Science, 2018, 61 (1), 113-137.

Kremer, Michael, "Integrating Behavioral Choice into Epidemiological Models of AIDS," Quarterly Journal of Economics, 1996, 111, 549-573.

— and Charles Morcom, "The effect of changing sexual activity on HIV prevalence," Mathematical Biosciences, 1998, 151, 99-122.

Logan, Trevon and Manisha Shah, "Face Value: Information and Signaling in an Illegal Market," Southern Economic Journal, January 2013, 79 (3), 529-564.

Maniloff, Peter and Ralph Mastromonaco, "The local employment impacts of fracking: A national study," Resource and Energy Economics, 2017, 49 (C), 62-85.

Mao, JM, W Tang, NS Wong C Liu, S Tang, C Wei, and JD Tucker, "Sex tourism among Chinese men who have sex with men: a cross-sectional observational study," BMC Public Health, 2018, 18(1).

Morris, Martina and Mirjam Kretzschmar, "Concurrent Partnerships and Transmission Dynamics in Networks," Social Networks, 1995, 17, 299-318.

_ and _ , "Concurrent Partnerships and the Spread of HIV," AIDS, 1997, 11 (5), 641-648.

National Institutes of Health, "Workshop Summary: Scientific Evidence on Condom Effectiveness for Sexually Transmitted Disease (STD) Prevention," Technical Report, Department of Health and Human Services, Hendon, Virginia July 2001. 
Oster, Emily, "Sexually Transmitted Infections, Sexual Behavior and the HIV/AIDS Epidemic," Quarterly Journal of Economics, May 2005, 120 (2), 467-515.

Posner, Richard A., Sex and Reason, 1st ed., Harvard University Press, 1992.

Potterat, John J., Richard B. Rothenberg, and Donald C. Bross, "Gonorrhea in street prostitutes: epidemiologic and legal implications," Sexually Transmitted Diseases, April-June 1979, 6 (2), $58-63$.

Satterwhite, CL, "Incidence, Prevalence, and Cost of Sexually Transmitted Infections in the United States," CDC Fact Sheet, 2013.

Street, B., "The Impact of Economic Opportunity on Criminal Behavior: Evidence from the Fracking Boom," Working Paper, 2019.

Willcox, R. R., "Prostitution and venereal disease: proportion of venereal disease acquired from prostitutes in Asia: a comparison with France, the United Kingdom, and the United States of America," British Journal of Venereal Disease, 1962, 38, 37-42.

Wilson, Riley, "Moving to economic opportunity: the migration response to the fracking boom," Available at SSRN 2814147, 2016. 


\section{Figure 1: STI Transmission Rate Effects}
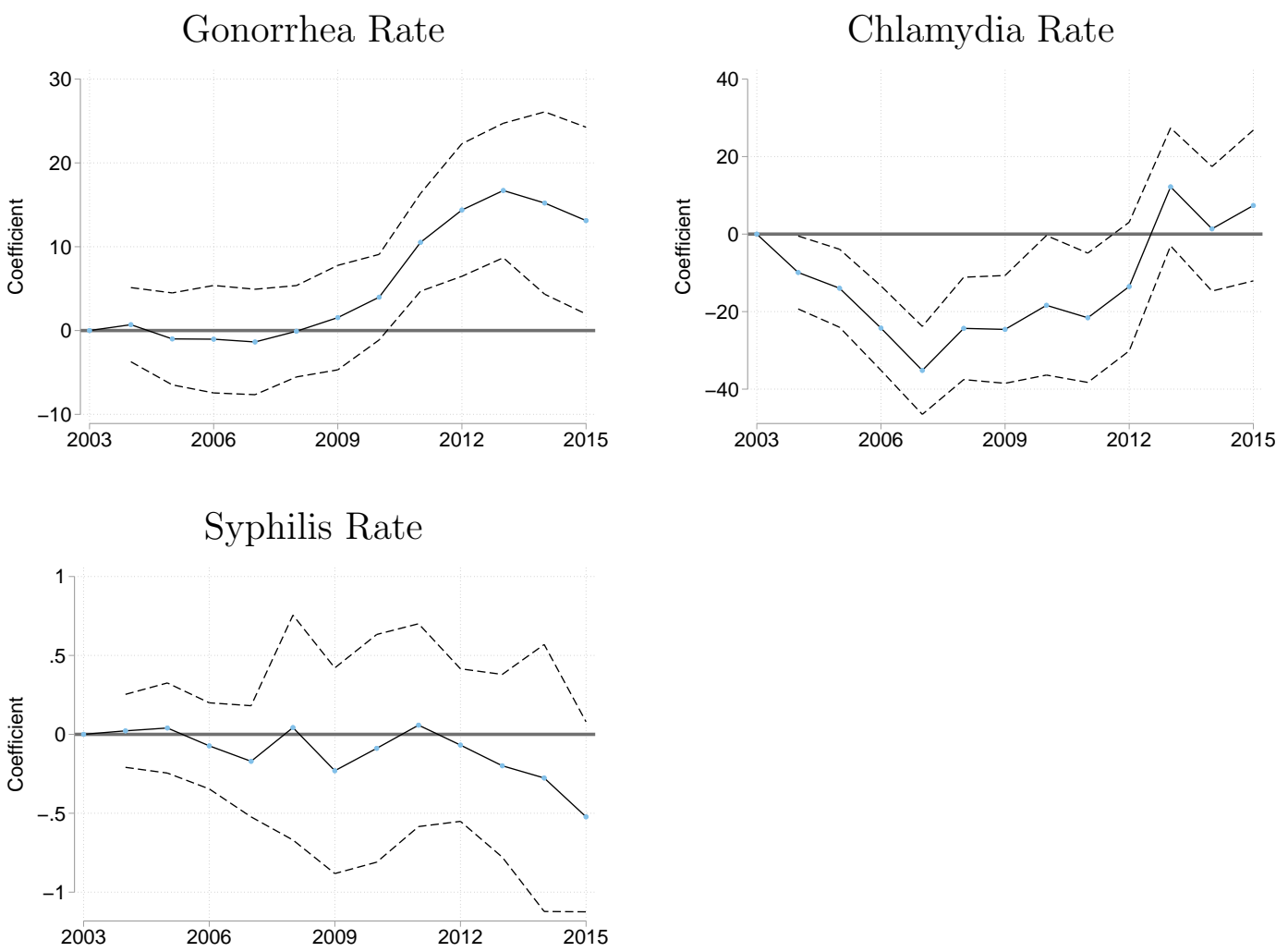

The graph plots coefficients and 95\% confidence intervals from estimating Equation (1). The dependent variable is given in the graph title. 


\section{Figure 2: Gonorrhea Rate, State Spillovers}

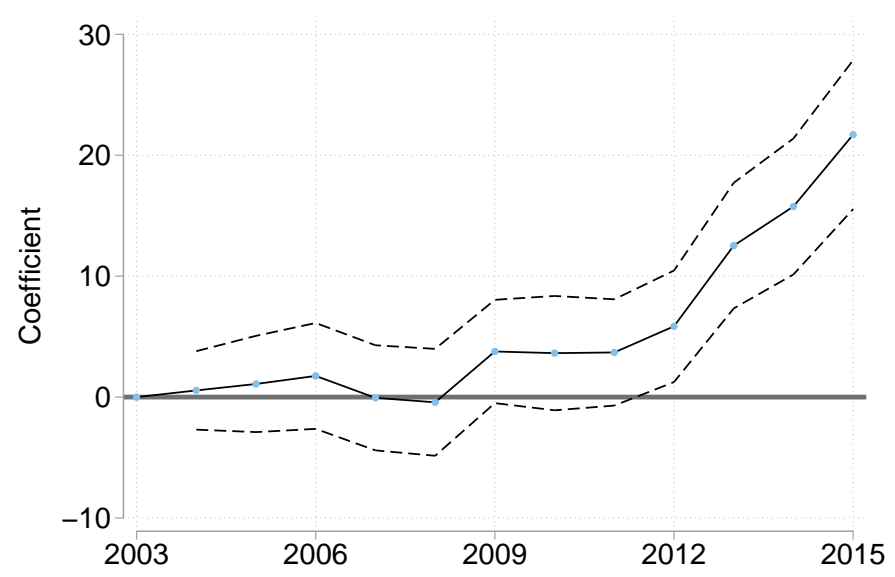

The graph plots coefficients and 95\% confidence intervals from estimating Equation (1) with gonorrhea rate as the dependent variable. The treatment group is defined as counties within a fracking state but not lying over a play, while counties lying over a play are excluded from the sample.

Figure 3: Gonorrhea Rate, Bordering County Spillovers

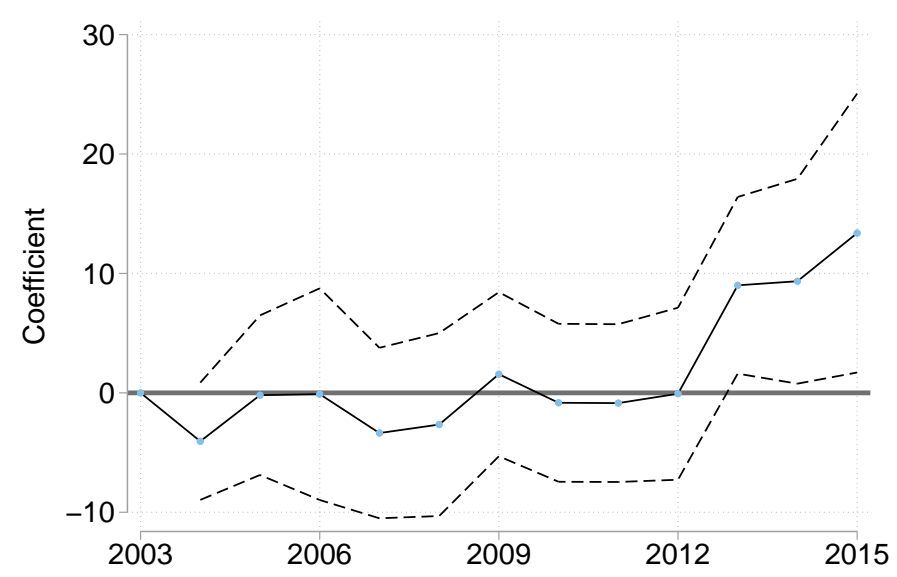

The graph plots coefficients and 95\% confidence intervals from estimating Equation (1) with gonorrhea rate as the dependent variable. The treatment group is counties bordering those lying over a booming play but not over a play themselves, while counties lying over a play are excluded from the sample. 
Figure 4: Gonorrhea Rate, State-year Fixed Effects

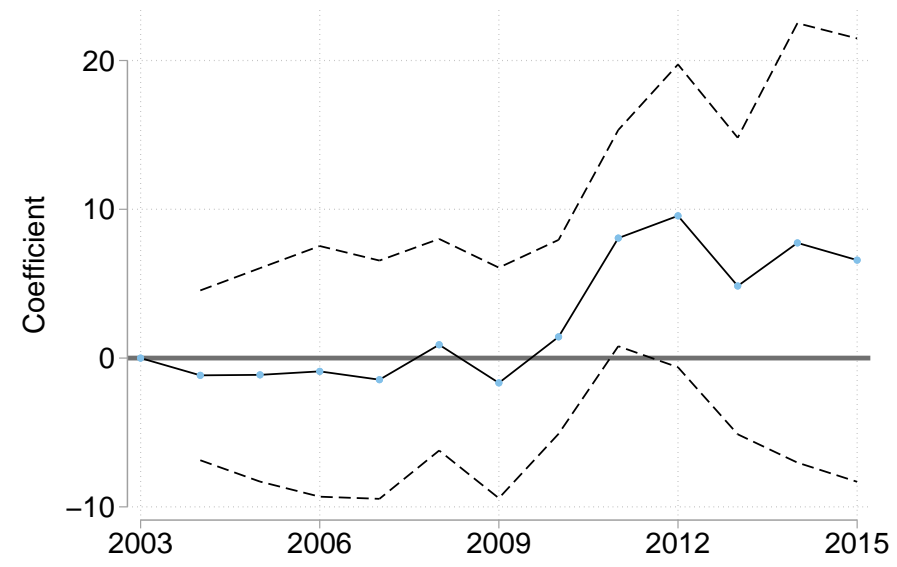

The graph plots coefficients and 95\% confidence intervals from estimating Equation (1) with state-by-year fixed effects included, and gonorrhea rate as the dependent variable.

Figure 5: TER Review Effects, All Counties $>30 \mathrm{k}$
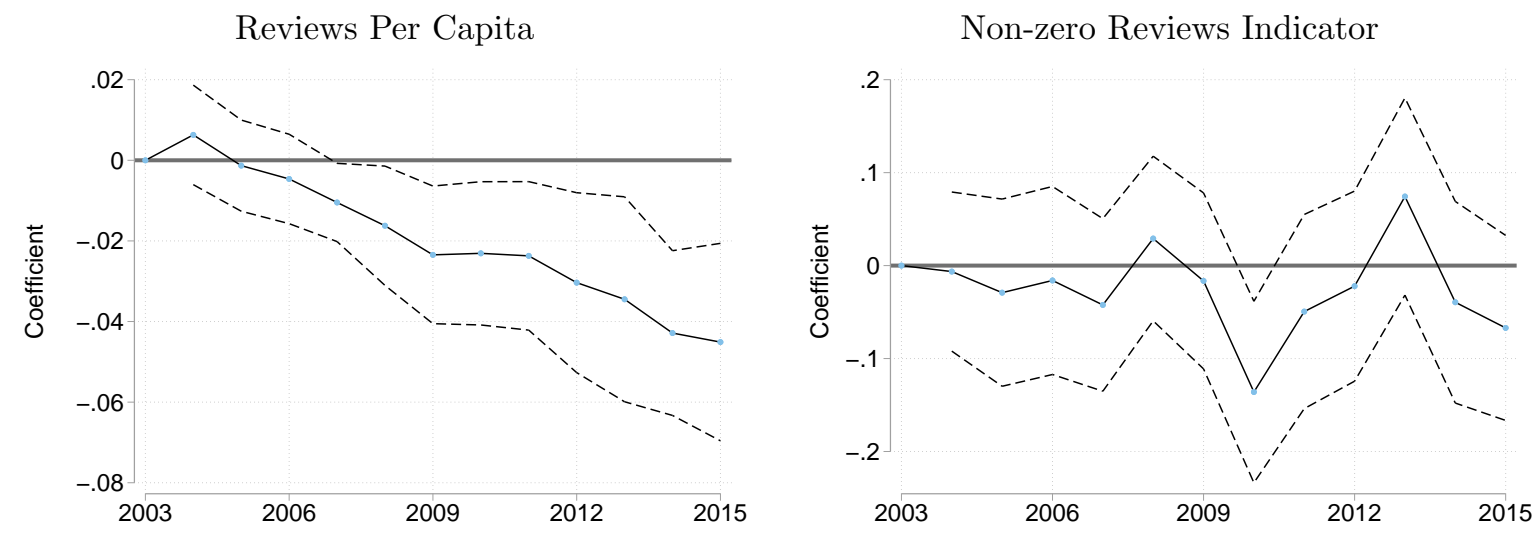

The graph plots coefficients and 95\% confidence intervals from estimating Equation (1) when limiting the sample to counties with at least 30,000 in population. The dependent variable is given in the graph title. 
Figure 6: TER Review Effects, Nearest 30k city treatment definition
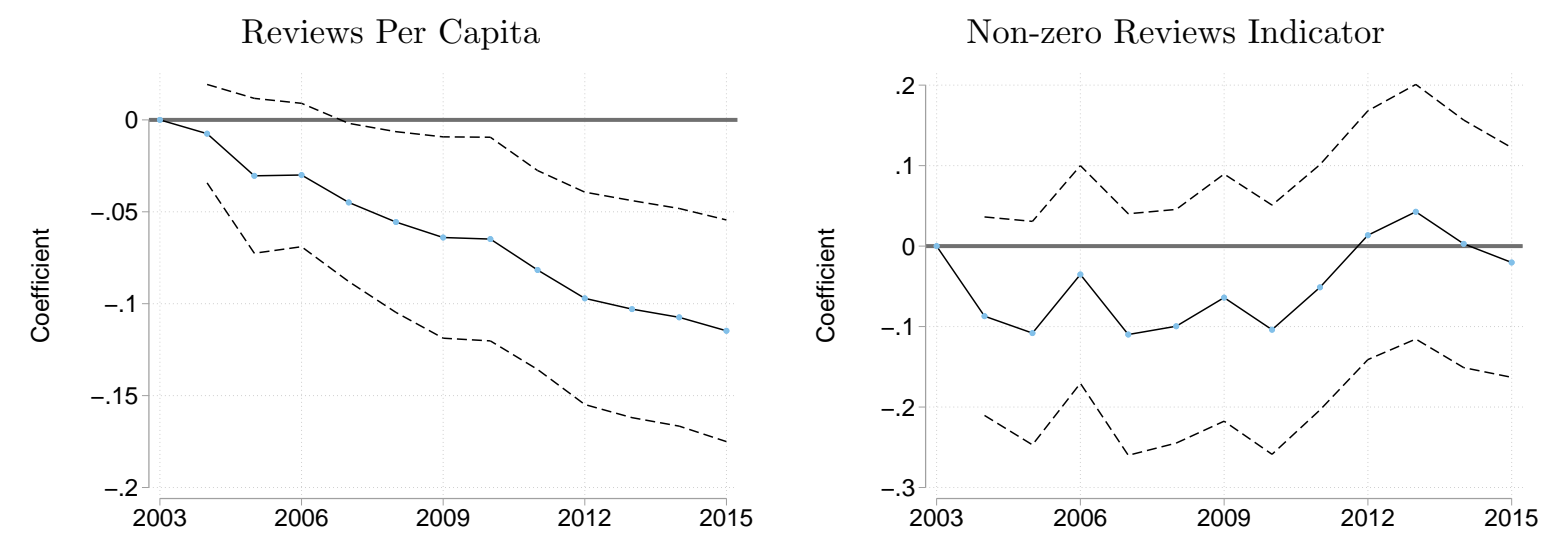

The graph plots coefficients and 95\% confidence intervals from estimating Equation (1) when limiting the sample to counties containing a city of at least 30,000, and defines treatment by whether it is the closest city to some part of a booming play. The dependent variable is given in the graph title.

Figure 7: STI Transmission Rate Effects, Restricted Sample
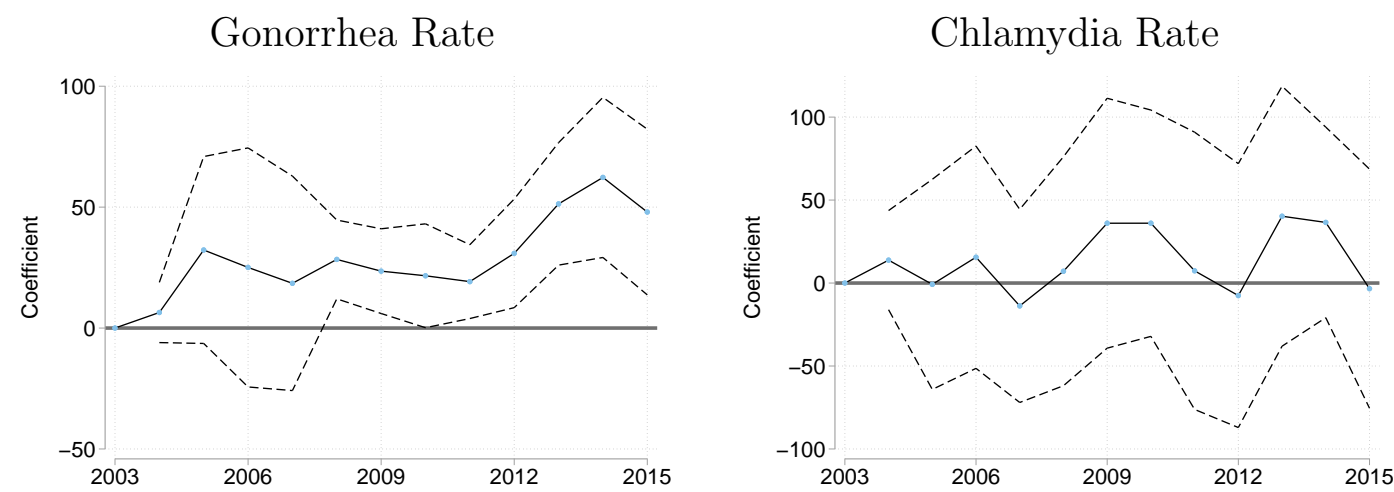

\section{Syphilis Rate}

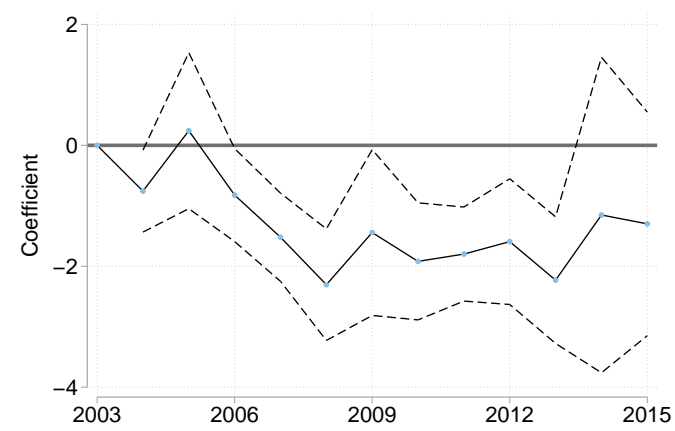

The graph plots coefficients and 95\% confidence intervals from estimating Equation (1) with the restricted sample and treatment group described in the text. The dependent variable is given in the graph title. 


\section{Figure 8: TER Review Effects, Restricted Sample}
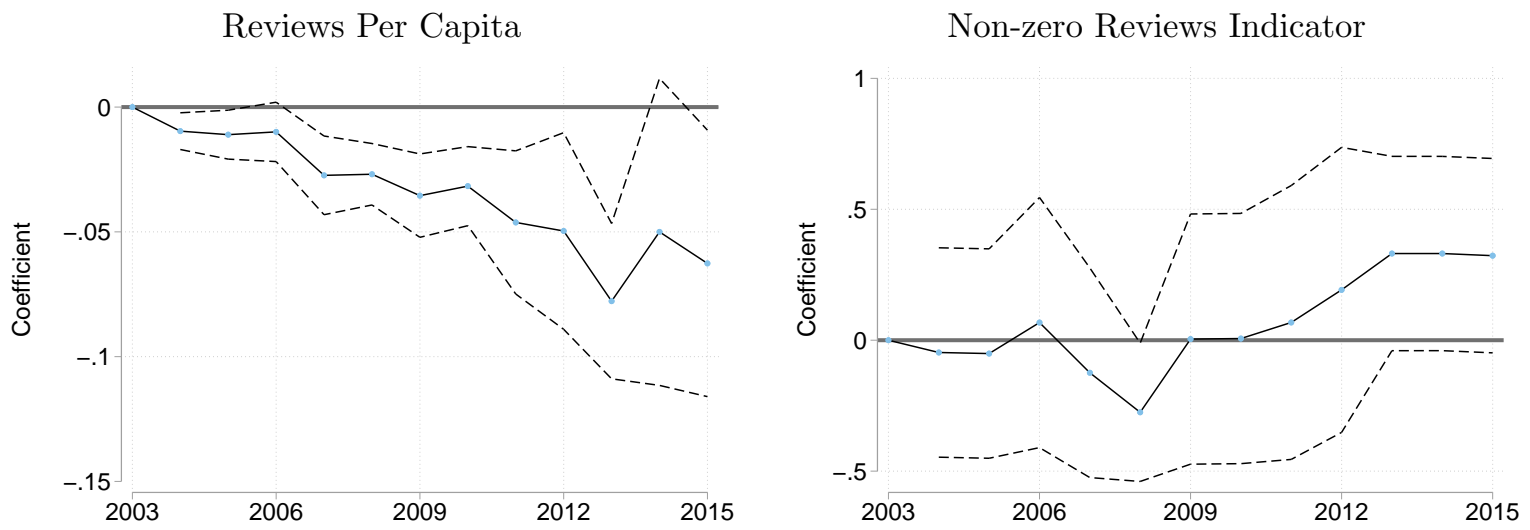

The graph plots coefficients and 95\% confidence intervals from estimating Equation (1) with TER reviews per capita as the dependent variable and with the restricted sample and treatment group described in the text. 


\section{A Appendix}

\section{Table A.1: Percentage Review \\ Location Assigned, Cross-Sectional Regression Results}

\begin{tabular}{lc}
\hline \hline & $(1)$ \\
& Percent Assigned \\
\hline Gonorrhea rate & 0.000 \\
& $(0.000)$ \\
Ln(income/cap) & $-0.129^{* * *}$ \\
& $(0.044)$ \\
Ln(population) & 0.074 \\
& $(0.048)$ \\
Sex ratio & -0.156 \\
& $(0.123)$ \\
Treatment & $0.071^{* *}$ \\
& $(0.031)$ \\
\hline$N$ & 1879 \\
\hline \hline
\end{tabular}

Notes: The dependent variable is the percentage of review locations assigned from 2003-2015. *,**,*** represent significance at $10 \%, 5 \%$ and $1 \%$, respectively.

Figure A.1: Percentage Review Location Assigned, Semi-Parametric Regression Results
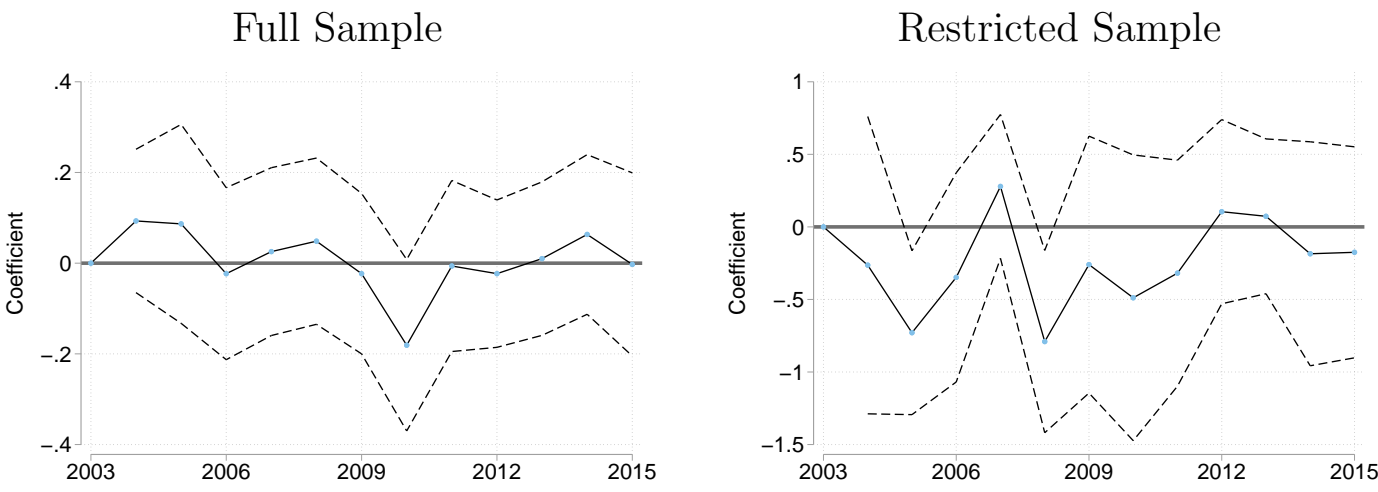

The graphs plots coefficients and 95\% confidence intervals from estimating Equation (1) with percentage of review locations assigned as the dependent variable. 
Table A.2: Summary Statistics

\begin{tabular}{|c|c|c|c|}
\hline Variable & $\begin{array}{c}\text { Treatment } \\
\quad(2003)\end{array}$ & $\begin{array}{c}\text { Control } \\
(2003)\end{array}$ & $\begin{array}{c}\text { Full Sample } \\
\text { (all years) }\end{array}$ \\
\hline Gonorrhea rate (Cases per 100,000) & $\begin{array}{c}45.2 \\
(77.9) \\
{[203]}\end{array}$ & $\begin{array}{c}69.1 \\
(100) \\
{[2912]}\end{array}$ & $\begin{array}{c}67.21 \\
(96.7) \\
{[40495]}\end{array}$ \\
\hline Chlamydia rate (Cases per 100,000 ) & $\begin{array}{c}176.1 \\
(156.0) \\
{[203]}\end{array}$ & $\begin{array}{c}216.7 \\
(199.8) \\
{[2912]}\end{array}$ & $\begin{array}{l}293.31 \\
(254.0) \\
{[40495]}\end{array}$ \\
\hline Syphilis rate (Cases per 100,000$)$ & $\begin{array}{c}0.3 \\
(1.3) \\
{[203]}\end{array}$ & $\begin{array}{c}0.8 \\
(4.1) \\
{[2912]}\end{array}$ & $\begin{array}{c}1.54 \\
(6.1) \\
{[40495]}\end{array}$ \\
\hline Reviews/1k cap & $\begin{array}{c}0.03 \\
(0.18) \\
{[86]}\end{array}$ & $\begin{array}{c}0.04 \\
(0.11) \\
{[1094]}\end{array}$ & $\begin{array}{c}0.06 \\
(0.15) \\
{[15340]}\end{array}$ \\
\hline $\ln ($ income/cap) & $\begin{array}{l}13.5 \\
(1.3) \\
{[203]}\end{array}$ & $\begin{array}{c}13.5 \\
(1.5) \\
{[2855]}\end{array}$ & $\begin{array}{c}13.77 \\
(1.5) \\
{[39732]}\end{array}$ \\
\hline $\ln (\mathrm{pop} / \mathrm{sq}$ mile $)$ & $\begin{array}{c}3.7 \\
(1.4) \\
{[203]}\end{array}$ & $\begin{array}{c}3.7 \\
(1.7) \\
{[2907]}\end{array}$ & $\begin{array}{c}3.74 \\
(1.7) \\
{[40430]}\end{array}$ \\
\hline $\mathrm{M} / \mathrm{F}$ ratio & $\begin{array}{c}1.0 \\
(0.1) \\
{[203]}\end{array}$ & $\begin{array}{c}1.0 \\
(0.1) \\
{[2905]}\end{array}$ & $\begin{array}{c}1.00 \\
(0.1) \\
{[40404]}\end{array}$ \\
\hline
\end{tabular}

The table shows means of each variable for the treatment and control groups as of 2003, and for the full sample for all years. Standard errors are shown in parenthesis and sample size used in the main regression specifications are in brackets. 
Figure A.2: US Shale Plays

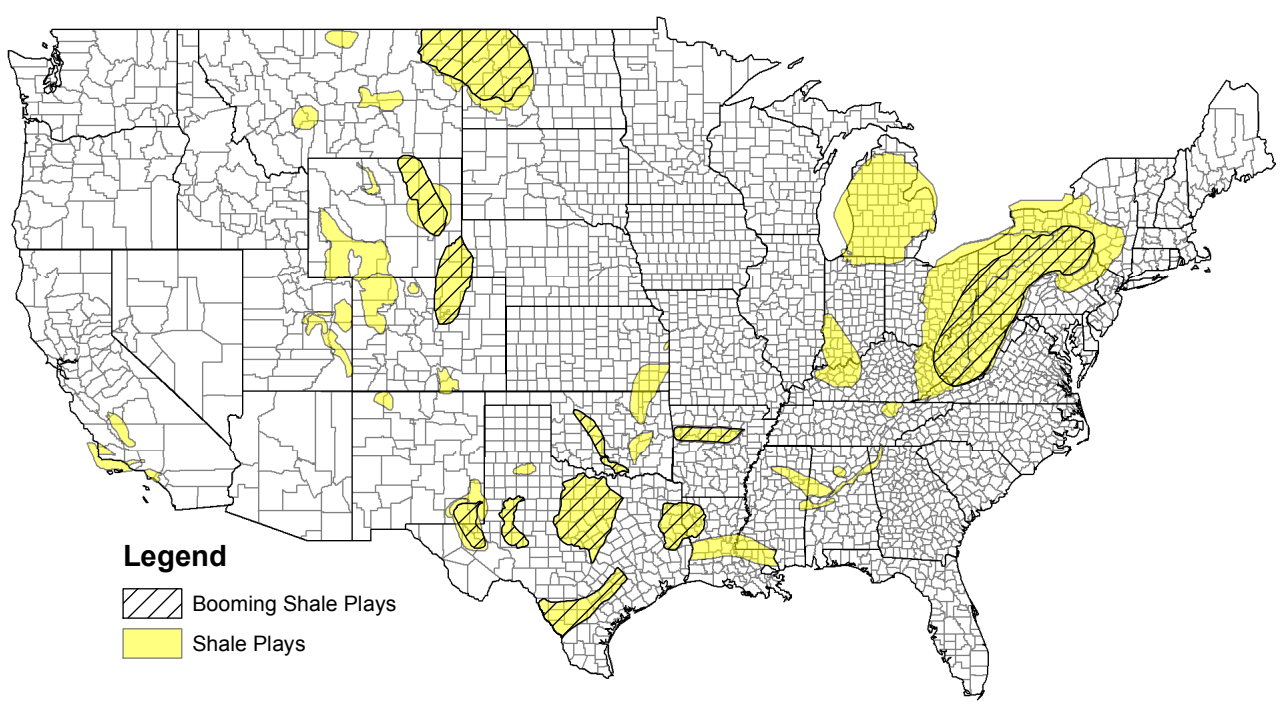

Source: Energy Information Administration

Figure A.3: Gonorrhea Rate, Fracking State Control Counties Excluded

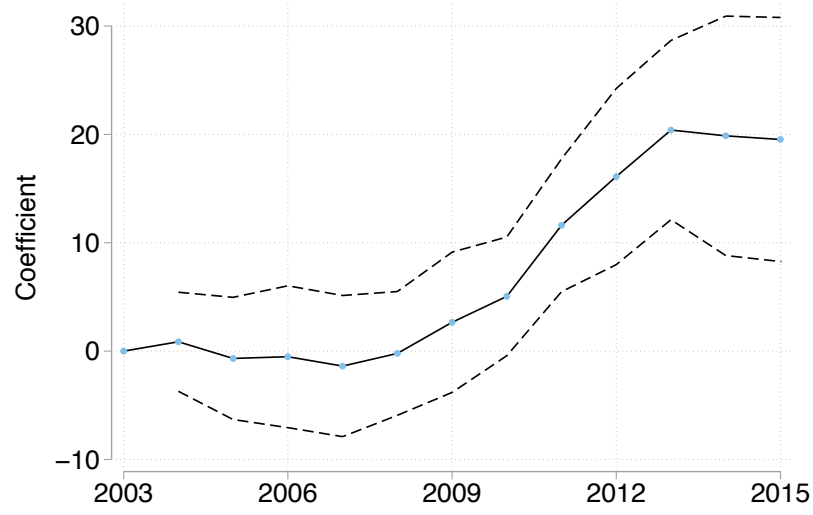

The graph plots coefficients and 95\% confidence intervals from estimating Equation (1) while excluding non-treatment counties within a state that includes a booming play and gonorrhea rate as the dependent variable. 


\section{Figure A.4: Gonorrhea Rate, ND Excluded}

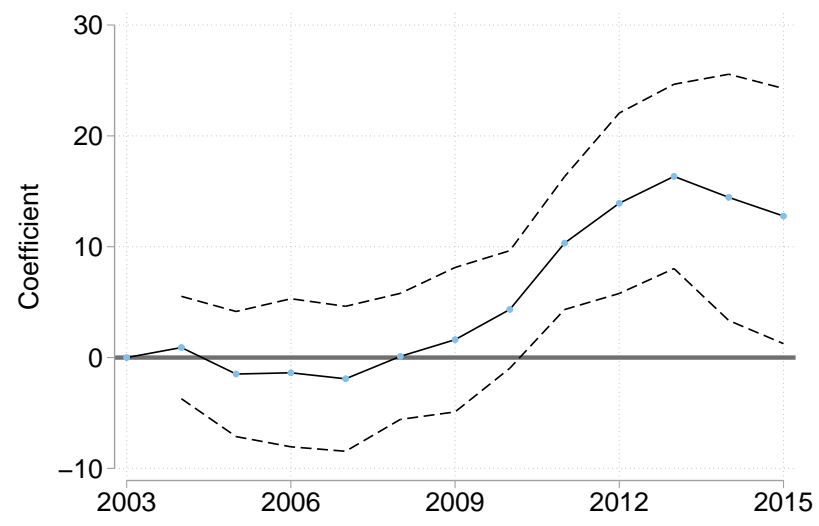

The graph plots coefficients and 95\% confidence intervals from estimating Equation (1) while excluding North Dakota counties and gonorrhea rate as the dependent variable.

Figure A.5: Gonorrhea Rate, Low-producing Treatments Excluded

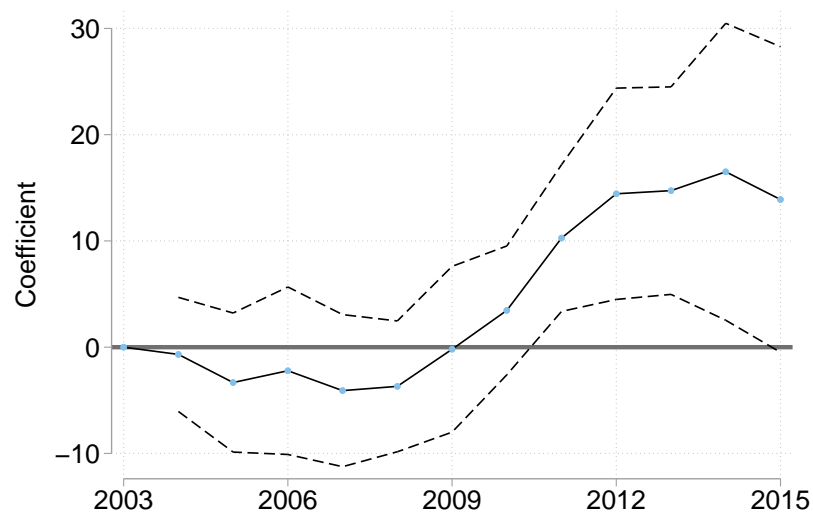

The graph plots coefficients and 95\% confidence intervals from estimating Equation (1) when excluding treatment counties that are below the 25th percentile in total dollar value of shale oil and gas production within the treatment group. Gonorrhea rate is the dependent variable. 
Figure A.6: Gonorrhea Rate, Employment Population Proxy

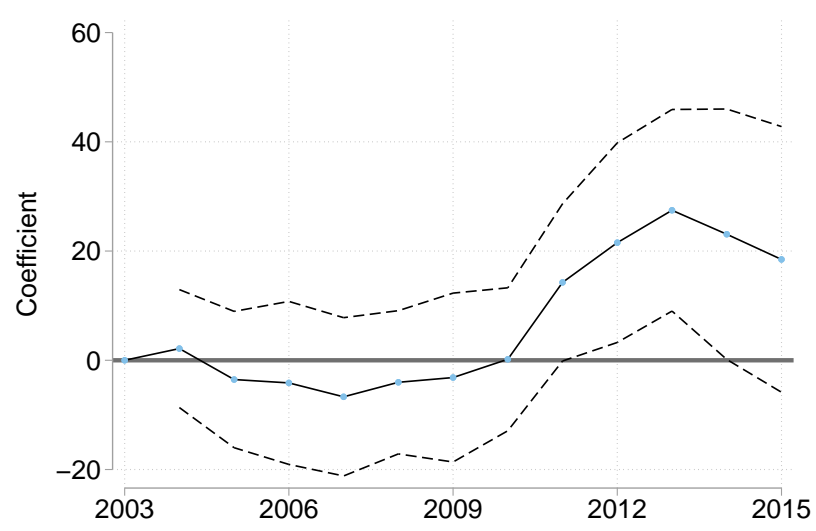

The graph plots coefficients and 95\% confidence intervals from estimating Equation (1) with gonorrhea rate calculated as cases per total employment rather than population.

Figure A.7: Gonorrhea Rate, Subsample of Counties Starting in 2000

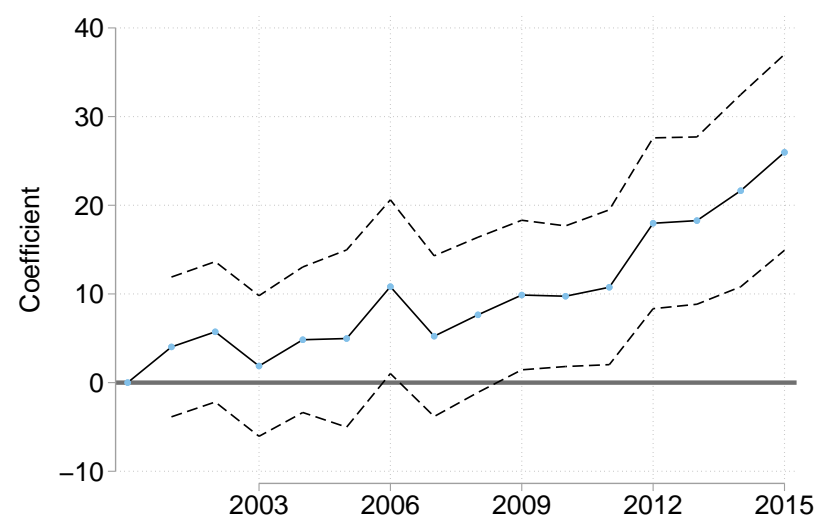

The graph plots coefficients and 95\% confidence intervals from estimating Equation (1) Using a subsample of counties with Gonorrhea data going back to 2000. 
Figure A.8: Male Gonorrhea Rate, State-Level Analysis

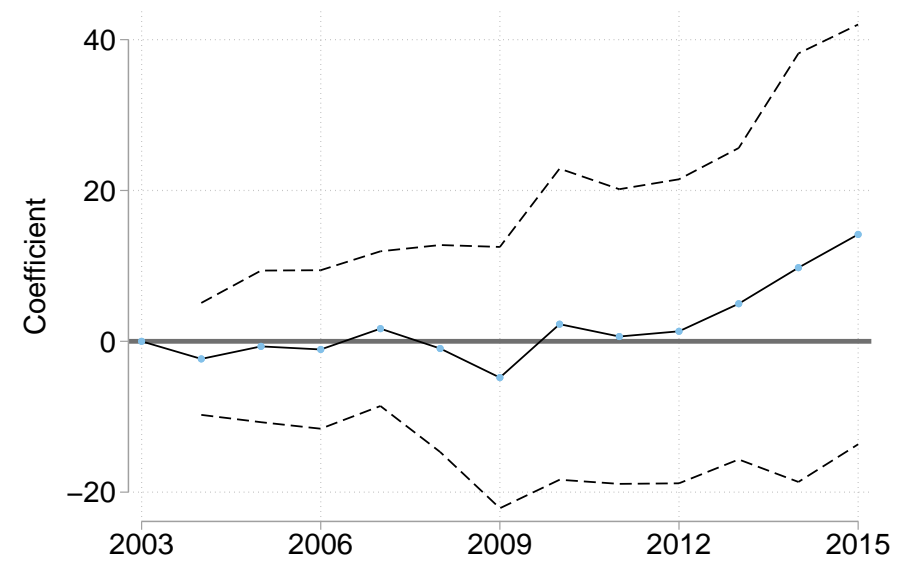

The graph plots coefficients and 95\% confidence intervals from estimating Equation (1) using state-level analysis with state and year fixed effects. with male gonorrhea rates as the dependent variable.

Figure A.9: Female Gonorrhea Rate, State-Level Analysis

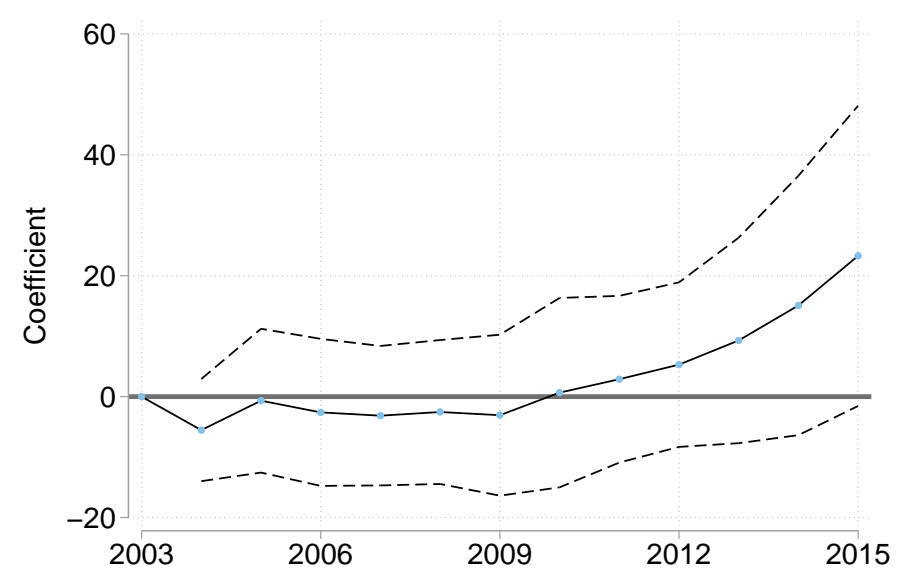

The graph plots coefficients and 95\% confidence intervals from estimating Equation (1) using state-level analysis and state fixed effects included with female gonorrhea rates as the dependent variable. 
Figure A.10: TER Review Effects, Controlling for County-Level Trends

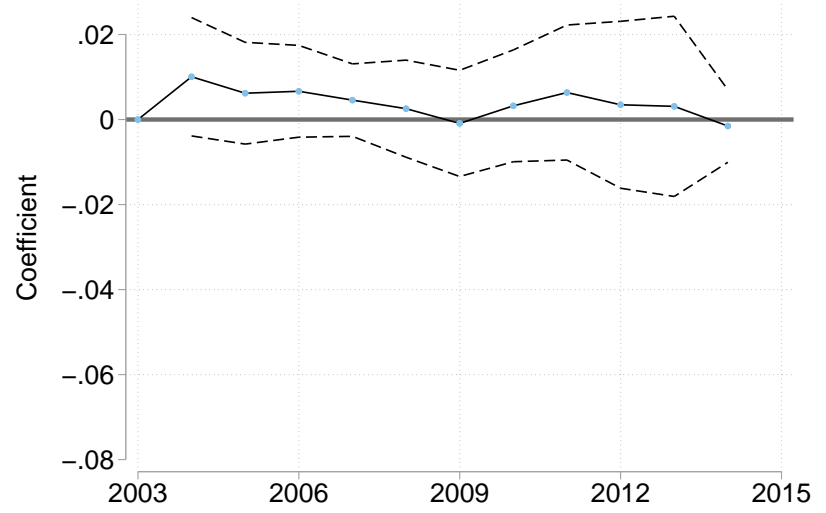

The graph plots coefficients and 95\% confidence intervals from estimating Equation (1) for TER reviews per capita while additionally controlling for county-level linear trends.

Figure A.11: Sex Ratio Effects, Restricted Sample

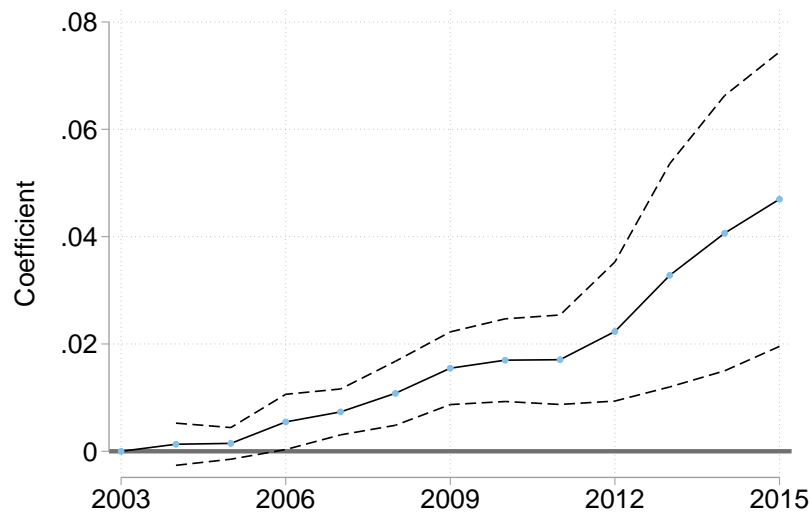

Notes: The graph plots coefficients and 95\% confidence intervals from estimating Equation (1) with sex ratio as the dependent variable and with the restricted sample and treatment group described in the text. 
Figure A.12: Treatment Effects, Placebo Cities
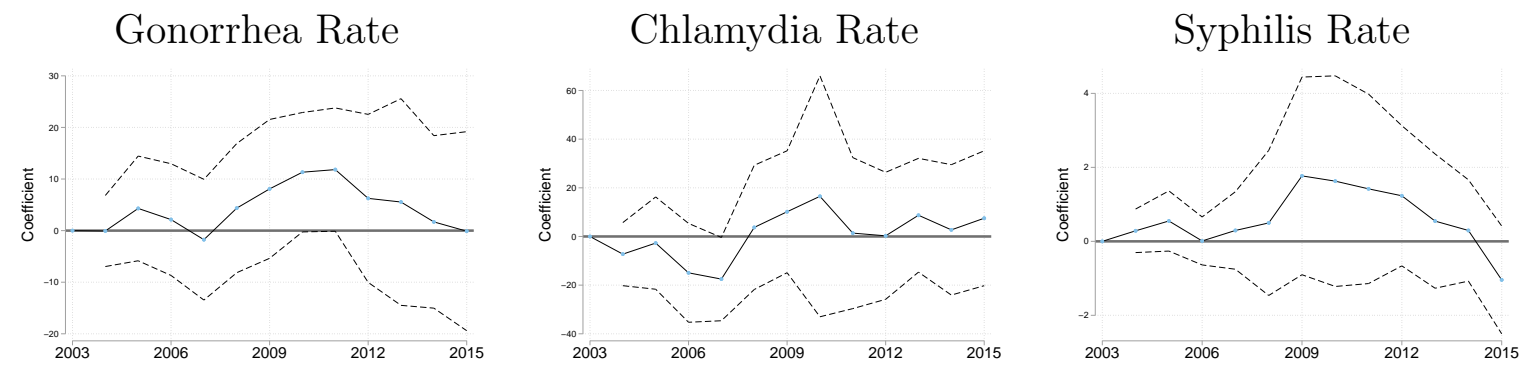

\section{Reviews Per Capita}
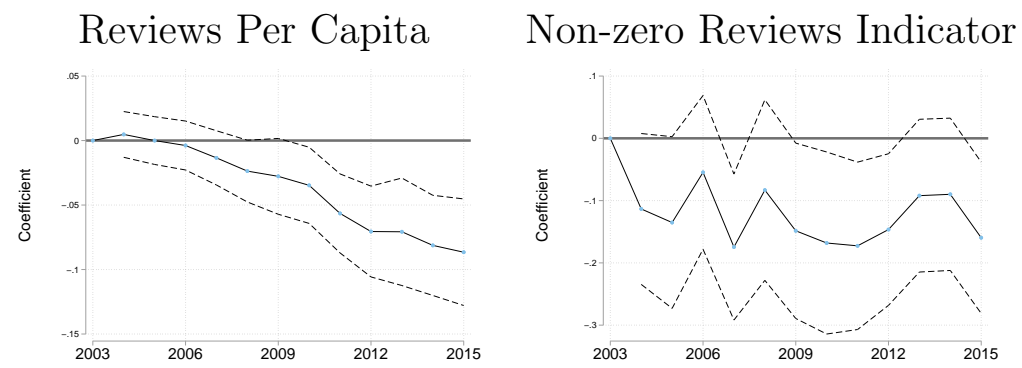

The graph plots coefficients and 95\% confidence intervals from estimating Equation (1) where the sample is limited to counties with cities and the treatment group is defined as counties containing cities near high fracking production but not isolated. The dependent variable is given in the graph title.

Figure A.13: Treatment Effects, Alternative Placebo Cities
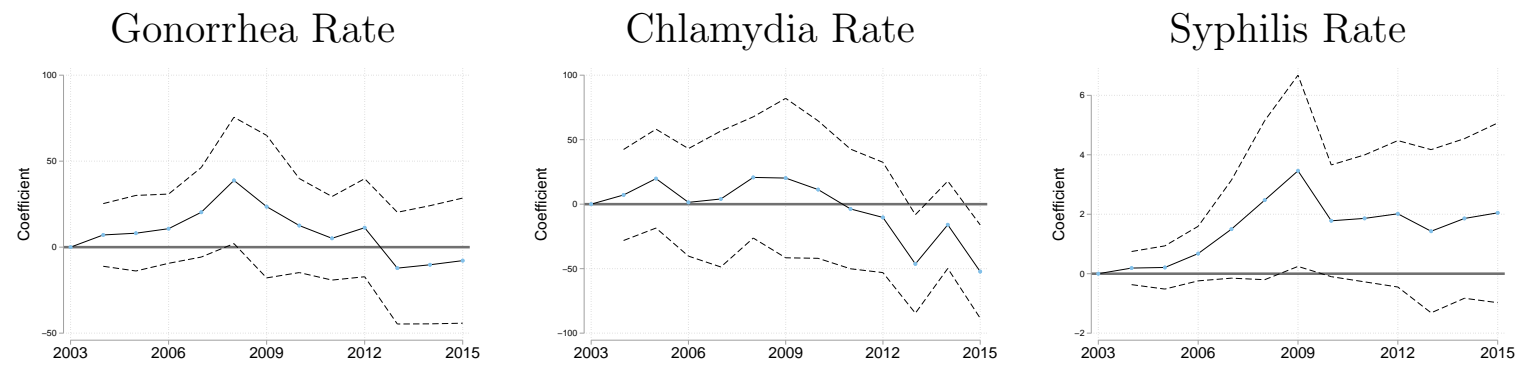

\section{Reviews Per Capita}
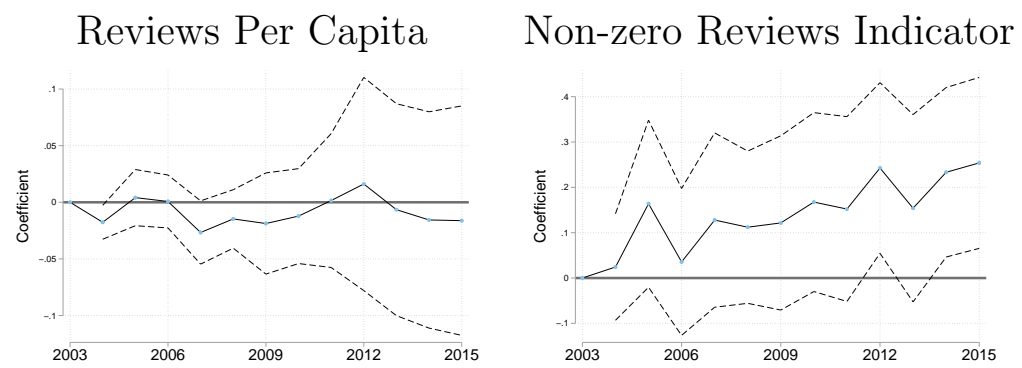

The graph plots coefficients and 95\% confidence intervals from estimating Equation (1) where the sample is limited to counties with cities outside of fracking states and the treatment group is counties containing isolated cities. The dependent variable is given in the graph title. 
Figure A.14: Additional Treatment Effects, Placebo Cities
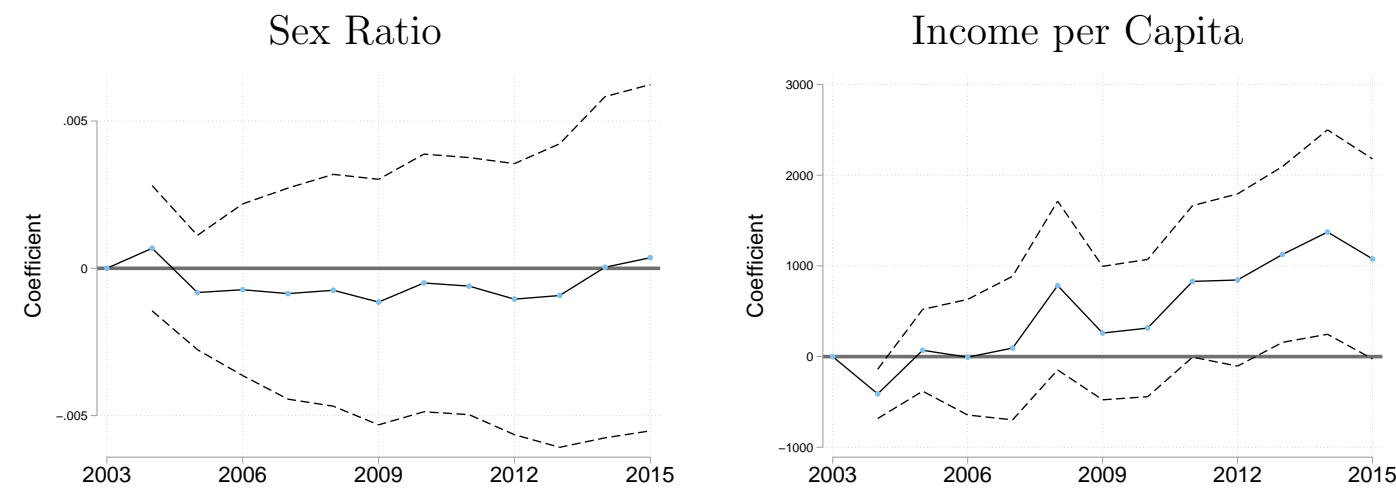

The graph plots coefficients and 95\% confidence intervals from estimating Equation (1) where the sample is limited to counties with cities and the treatment group is defined as counties containing cities near high fracking production but not isolated. The dependent variable is given in the graph title.

Figure A.15: Income per Capita Effects, Restricted Sample

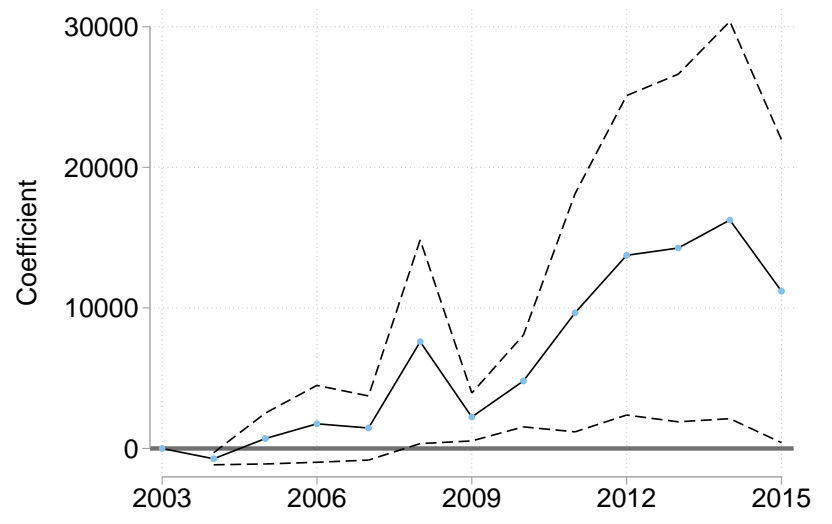

The graph plots coefficients and 95\% confidence intervals from estimating Equation (1) with income per capita as the dependent variable and with the restricted sample and treatment group described in the text. 


\section{B Additional Case Study Analysis}

In Section 5.2 we examined the effects on STIs and sex work activity in areas with conditions such that the fracking boom might have especially pronounced effects on these outcomes by running restricted sample regressions with these areas as the treatment group. In this section we extend this analysis by performing individual case studies. This provides additional robustness and insights into specifically where effects are largest.

We first use state-level analysis to evaluate STI and prostitution effects in North Dakota, which is an outlier state in terms of the economic impact of the fracking boom due to its especially high shale production and low population density. For North Dakota we use both OLS with randomization inference and a synthetic control analysis. We then perform synthetic control analysis for each of the restricted sample treatment counties analyzed in Section 5.2. Synthetic controls is a method established by Abadie and Gardeazabal (2003) and Abadie et al. (2010) that compares a single treated unit to a weighted combination of potential control units, with weights chosen so that the combination most closely resembles the treated unit along a vector of predictor variables before the treatment is applied (see the aforementioned papers for more detail).

\section{B.1 North Dakota Case Study}

Figure B.1 shows the unconditional means over time of gonorrhea rates and online prostitution reviews per capita for both North Dakota and the rest of the country as a whole. Both variables start at a much lower pre-boom baseline for North Dakota, with prostitution review activity in particular being nearly zero. Both variables then experience a major increase coinciding with the timing of the boom. At the national level, gonorrhea rates remain relatively flat, while reviews show a sharp increase starting in 2011, reflecting increased popularity of the website. By the end of the period, gonorrhea rates in North Dakota are close to the national level. Reviews per capita remain significantly smaller, but the gap is narrower and the graph is suggestive of an extensive-margin effect on review activity.

For a stronger causal analysis of the effects in North Dakota we first estimate a two- 
Figure B.1: North Dakota vs. Rest of Country, Unconditional

Gonorrhea Rate (Cases per 100,000)

Reviews per capita (x 1000)
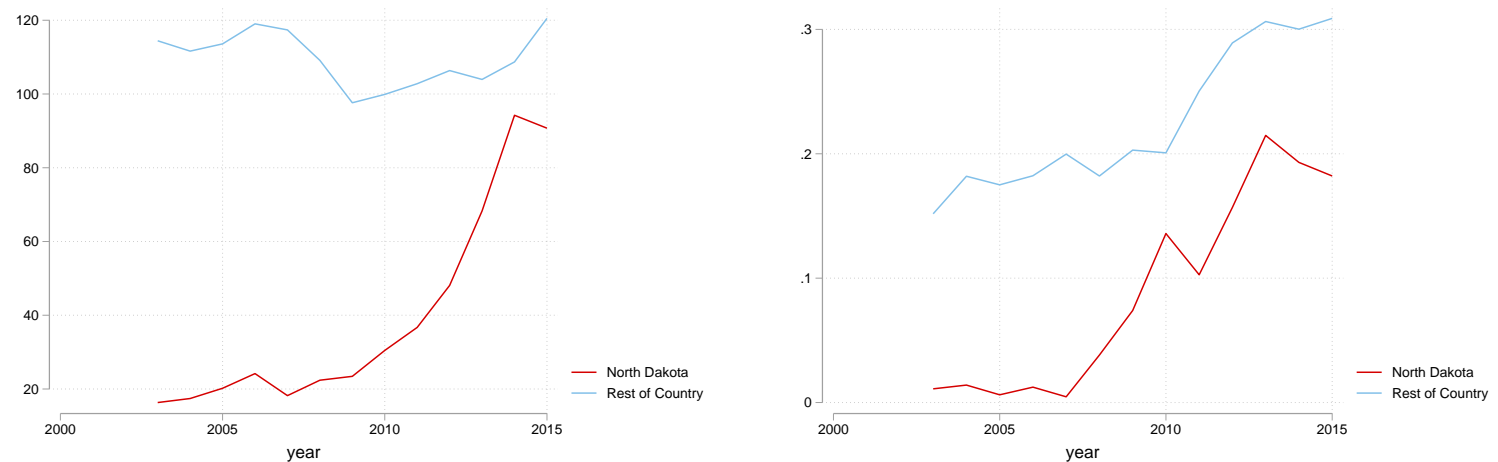

way fixed effects model similar to Equation (1) with North Dakota as the sole treatment state, and states that do not lie over a booming play as controls. We choose our treatment year as 2008, as this is two years before shale production in the Bakken play begins a sustained major increase. We choose two years before the production spike to account for the well construction period that accounts for the actual influx of labor. We obtain p-values by randomization inference, which involves running the same model for each non-fracking state and calculating a p-value based on where the North Dakota effect lies in the distribution of "placebo" effects.

For both gonorrhea and prostitution reviews per capita we run the analysis for both the non-transformed rates and using log transformations, which can yield different results since for both outcomes North Dakota's pre-treatment levels are significantly lower than the national average. Results for the two-way fixed effects estimation of gonorrhea effects are presented in Table B.1. We find that fracking was associated with nearly 42 extra gonorrhea cases per 100,000 people per year. Using the log transformation suggests that fracking led to a near-doubling of gonorrhea transmission relative to the counterfactual. The table also shows the 5th and 95th percentile of the absolute value of estimated effects for placebo states, and the two-tailed p-value, which is calculated as the rank of the absolute value of the North Dakota effect divided by the total number of states. For the non-transformed gonorrhea rate, the North Dakota effect is significant at a $10 \%$ level. For the natural log, where North Dakota has the largest effect in the sample, the estimate is 
significant at a $5 \%$ level.

Table B.2 shows the two-way fixed effects model results for prostitution reviews. For non-transformed reviews per capita, there is a negligible estimated effect. But as shown in Figure B.1, North Dakota's reviews begin at a very low baseline relative to the rest of the country, so the relative percentage change is much larger. This is reflected in the results for log reviews per capita, where the North Dakota effect has the largest magnitude in the sample. But this result should still be viewed with caution. For North Dakota counties (and the additional case study counties analyzed below), we manually checked that each review assigned to a county was correctly assigned, which significantly reduced the number of reviews assigned to North Dakota since it had very little actual pre-treatment review activity. Starting from a lower baseline makes the percentage increase during the fracking boom larger. We did not manually check every US county for practical reasons. Therefore, although it is clear that there was a large percentage increase in reviews relative to the rest of the country during the boom, the p-value for this particular outcome may be artificially low. Figure B.2 provides histograms of the placebo distributions for all four outcomes, including where the North Dakota effect falls within. ${ }^{28}$

Table B.1: North Dakota Gonorrhea Effects, OLS with Randomization Inference

\begin{tabular}{lcc}
\hline Dependent variable: & Gonorrhea rate & $\operatorname{Ln}$ (Gonorrhea rate) \\
\hline North Dakota effect & 41.829 & 0.914 \\
Placebo 5th percentile & 1.119 & 0.004 \\
Placebo 95th percentile & 49.915 & 0.503 \\
Two-tailed p-value & 0.08 & 0.03 \\
\hline No. of Control States & 36 & 36 \\
\hline \multicolumn{2}{l}{ Table presents 5th and 95th percentile confidence intervals from placebo-based } \\
inferential calculations, and p-values from a two-tailed test. & Gonorrhea rate is \\
cases per 100,000 people.
\end{tabular}

We next estimate a synthetic control model for North Dakota, using the same four outcomes. Our predictor variables are the outcome variable of interest in 2007, 2005 and 2003. Donor states include all states that do not contain a booming play. ${ }^{29}$ This analysis

\footnotetext{
${ }^{28}$ The outlier effect for reviews per capita is for Washington DC.

${ }^{29}$ For gonorrhea rate, North Dakota's synthetic control is $77.1 \%$ New Hampshire and small percentages of many other states. For log gonorrhea rate it is $55.3 \%$ New Hampshire, $9.4 \%$ Idaho and small percentages of many other states. For prostitution reviews the synthetic control is $95.0 \%$ Delaware and $5.0 \%$ Iowa. For log reviews it is $65.2 \%$ Delaware and $34.8 \%$ Iowa.
} 
Table B.2: North Dakota Review Effects, OLS with Randomization Inference

\begin{tabular}{lcc}
\hline Dependent variable: & Reviews per capita & Ln(Reviews per capita) \\
\hline North Dakota effect & 0.009 & 2.055 \\
Placebo 5th percentile & 0.005 & 0.043 \\
Placebo 95th percentile & 0.221 & 1.257 \\
Two-tailed p-value & 0.91 & 0.03 \\
\hline No. of Control States & 35 & 35 \\
\hline Table presents 5th and 95th percentile confidence intervals from placebo-based inferential \\
calculations, and p-values from a two-tailed test. Reviews per capita is reviews per 1,000 \\
people.
\end{tabular}

Figure B.2: OLS Placebo Distributions

Gonorrhea Rate

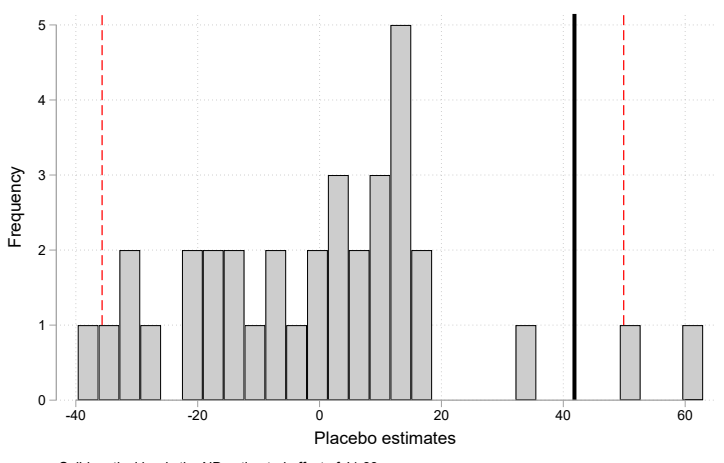

Reviews per Capita

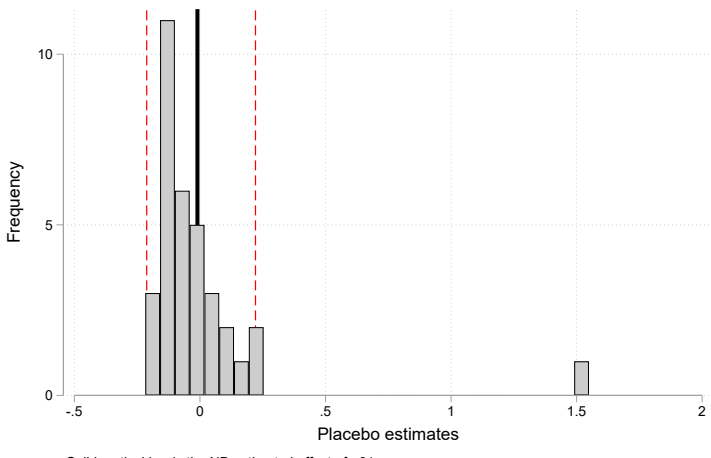

Solid vertical bar is the ND estimated effect of -.01
Ln(gonorrhea Rate)

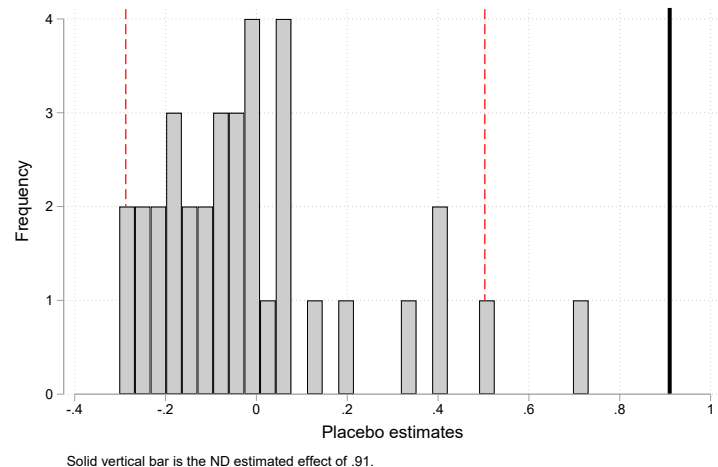

Ln(Reviews per Capita)

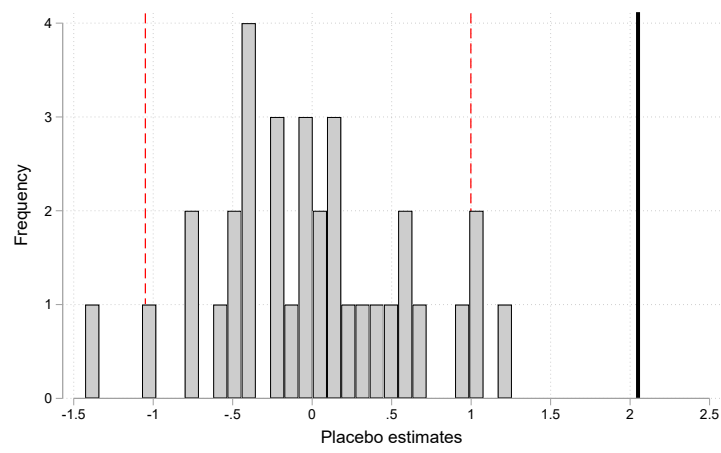

Solid vertical bar is the ND estimated effect of 2.05 .

The graphs show histograms of estimated placebo effects for the outcome indicated by the caption. Dotted lines indicate 5th and 95th percentiles of the placebo distribution, and the solid vertical bar is the estimated effect for North Dakota.

is shown in Figure B.3, which shows the North Dakota results along with the placebo distributions constructed by running synthetic controls for each donor state. The results are qualitatively similar to the two-way fixed effects analysis, with large and statistically 
significant $^{30}$ (at at least a $10 \%$ level) effects later in the fracking boom for all outcomes except non-transformed reviews (although we do estimate a somewhat large effect for this outcome, unlike with OLS).

\section{B.2 Additional Case Studies}

We next perform synthetic control analysis for the seven restricted sample treated counties. For this analysis the donor pool of comparison counties are those within the same census division as the treated county, but dropping all other counties within states that contain a booming play, since significant state spillover effects were found in Section 5.1.2. The exceptions to these donor pool criteria are the three Texas counties, because the West South Central division includes only treated states. Therefore for these counties we draw comparisons from the Mountain West division, which is chosen since western Texas has a similarly arid climate and lower population density.

Similar to the North Dakota analysis above, the treatment locations are considered treated two years prior to oil or gas production beginning a major, sustained increase in the nearby high-producing counties. Figure B.4 shows the dollar value of oil and gas production from new wells nearby the treated county by year for each case study, with the vertical line representing the treatment year. This turns out to be 2008 for every case except Parkersburg, which is 2011. ${ }^{31}$

For each case study, we run synthetic control analysis for both gonorrhea transmission rates and prostitution reviews per capita. As with North Dakota, our matching variables are the outcome variable one, three and five years prior to the treatment year. The results shown in Figures B.5-B.11 show mixed evidence of effects for both outcomes for these case studies. For gonorrhea transmission, Minot, Parkersburg, Midland and Odessa display positive and large effects, while none of the others display negative effects (note that for Hobbs, NM, the pre-treatment match is very poor, so synthetic controls are ill-suited for this particular case). For prostitution, Minot, Midland, Odessa, and Casper, WY expe-

\footnotetext{
${ }^{30} \mathrm{P}$-values are again based on where the North Dakota estimate ranks in the placebo distribution of effects. Treatment effects and p-values can be estimated separately for each post-treatment period.

${ }^{31}$ These graphs are meant to show the timing of nearby production booms, and since they include different numbers of counties for different cases, the magnitudes are not readily comparable.
} 
Figure B.3: North Dakota Synthetic Controls for Gonorrhea Rate and Reviews per Capita

Gonorrhea Rate

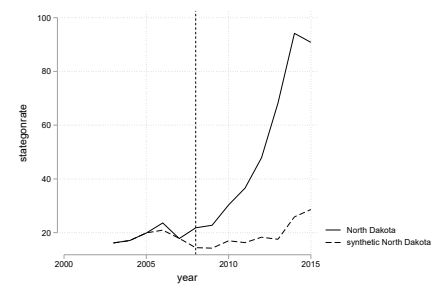

Ln(gonorrhea Rate)

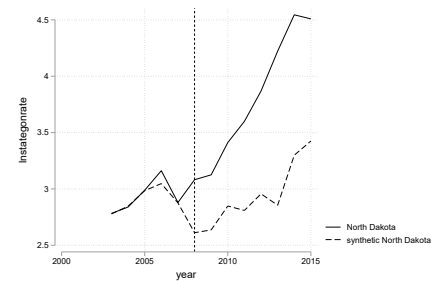

Reviews per Capita

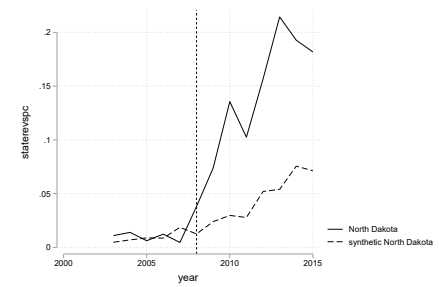

Ln(Reviews per Capita)

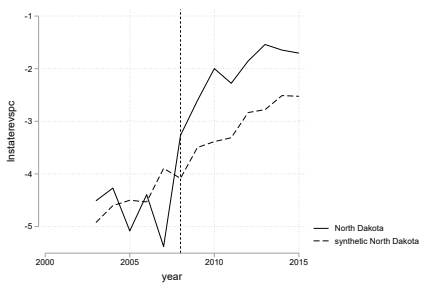

Gonorrhea Rate Gap

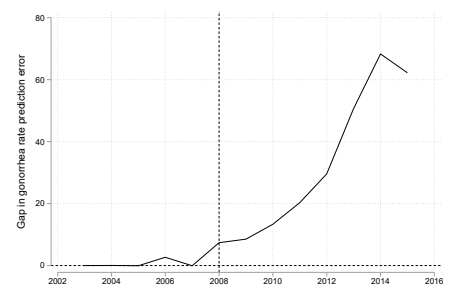

Ln(gonorrhea Rate) Gap

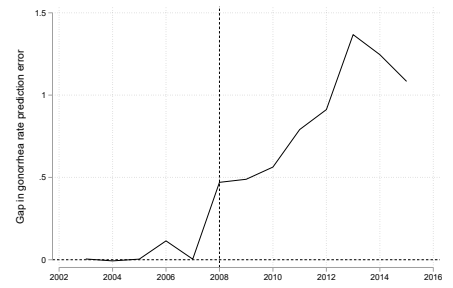

Reviews per Capita Gap

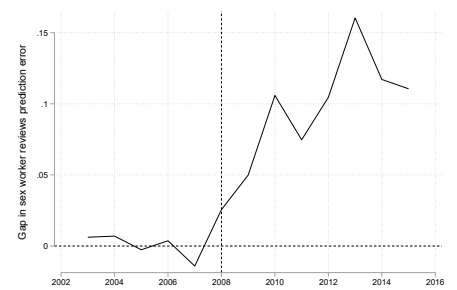

Ln(Reviews per Capita) Gap

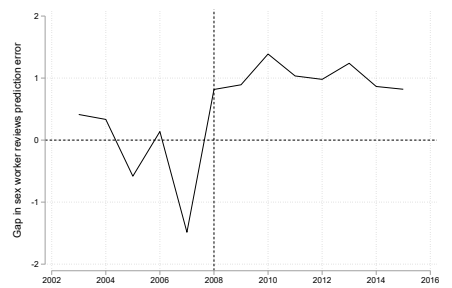

Gonorrhea Rate Placebo

Distribution

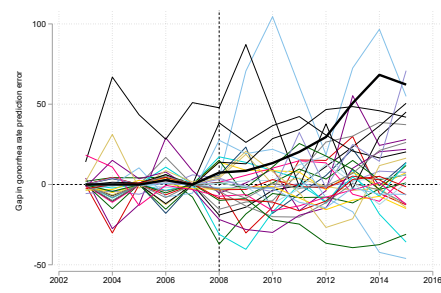

Ln(gonorrhea Rate) Placebo Distribution

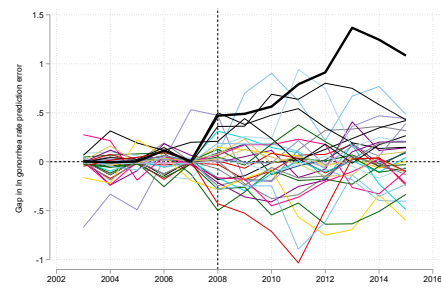

Reviews per Capita Placebo Distribution

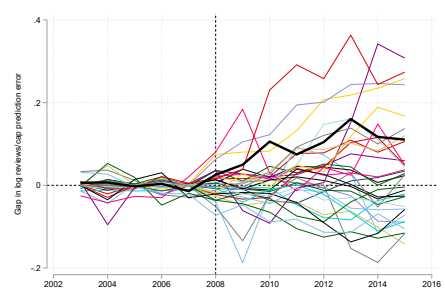

Ln(Reviews per Capita) Placebo Distribution

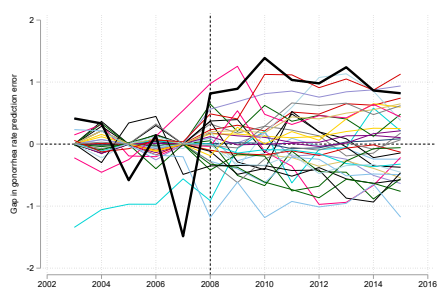

The graphs plot the North Dakota synthetic control results for each of the four outcomes. The first column plots the outcome for North Dakota vs. the synthetic control over time, and the second column plots the gap between the two. The third column plots the gap for each placebo state, along with North Dakota in bold.

rience positive effects, while none of the others experience negative effects. Parkersburg, WV initially experiences large positive effects on reviews that are diminished by the end 


\section{Figure B.4: New Fossil Fuel Production Near Case Study Counties}

Ward, ND (Minot)

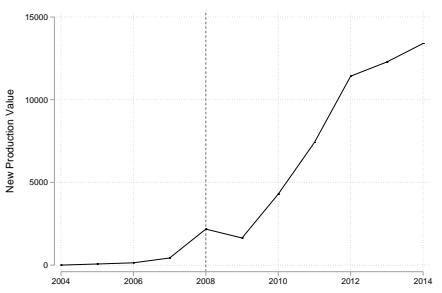

Midland/Odessa, TX

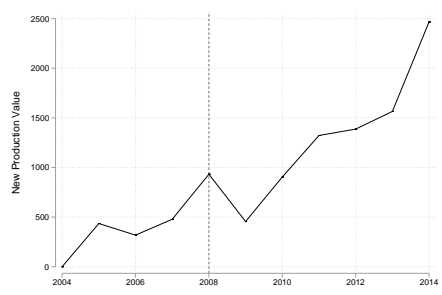

Wood, WV (Parkersburg)

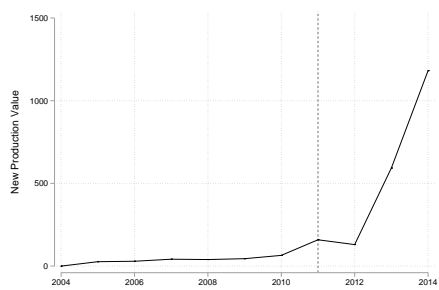

Lea, NM (Hobbs)

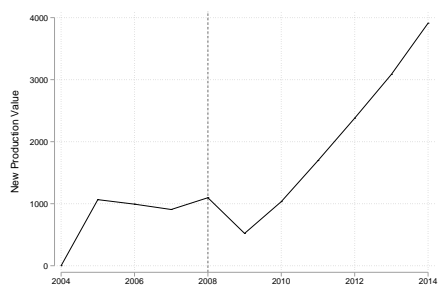

Webb, TX (Laredo)

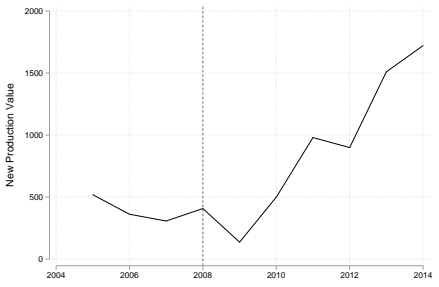

Natrona, WY (Casper)

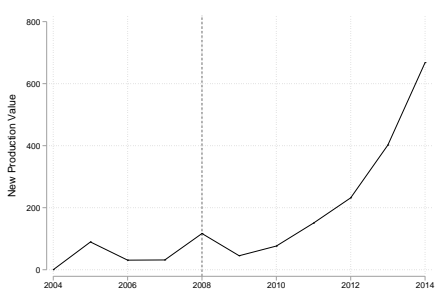

The graphs plot total dollar value of new shale oil and gas production in North Dakota or near the case study county of interest. The vertical line indicates the treatment date, which is selected as two years before production begins a sustained increase.

of the sample period. For the case study counties with positive review effects, the general pattern is zero or near-zero review activity prior to the treatment year, followed by a sharp increase that is not matched by the synthetic control.

Although these are somewhat volatile variables at the individual county level and not all case studies show the same patterns, we see this as moderate evidence of intensivemargin average effects on gonorrhea transmission in remote, highly productive fracking areas, along with extensive margin effects on prostitution, which is broadly consistent with the restricted sample regressions shown in Section 5.2. ${ }^{32}$

\footnotetext{
${ }^{32}$ One possible mechanism for increased prostitution is cities and counties failing to increase the police force in proportion with population growth, which may lead to a general increase in crime. We explore this by running synthetic controls on our case study counties with officer counts per capita as the outcome variable. However, we do not find a link between officer per capita effects and prostitution effects. These results are available upon request.
} 
Figure B.5: Synthetic Control Results for Ward, ND (Minot)

Gonorrhea Rate

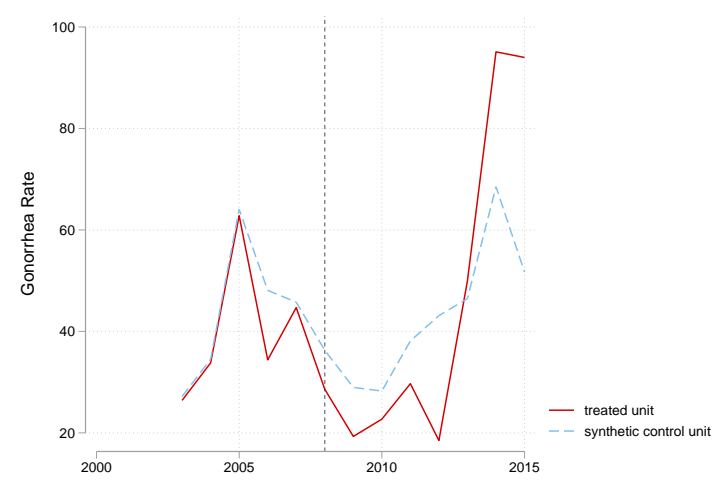

Reviews per capita

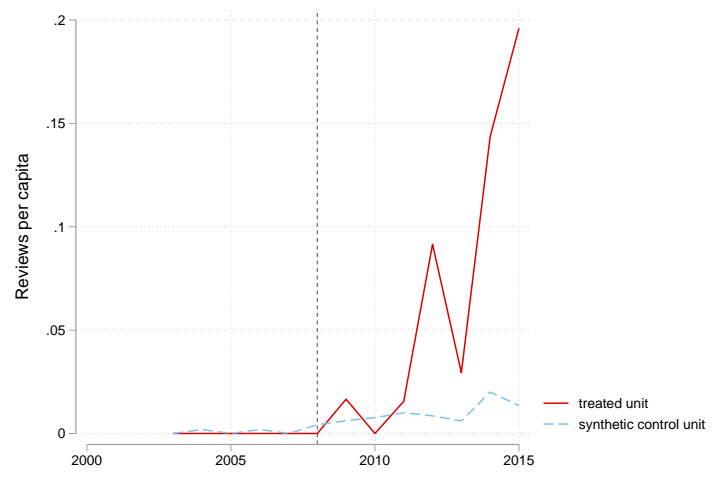

Figure B.6: Synthetic Control Results for Wood, WV (Parkersburg)

Gonorrhea Rate

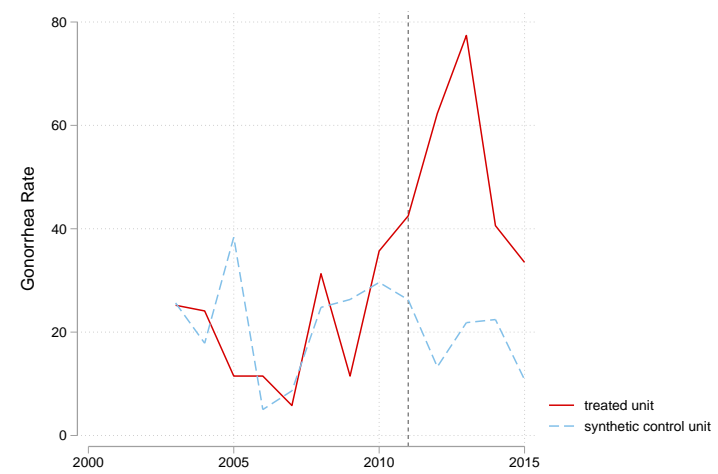

Reviews per capita

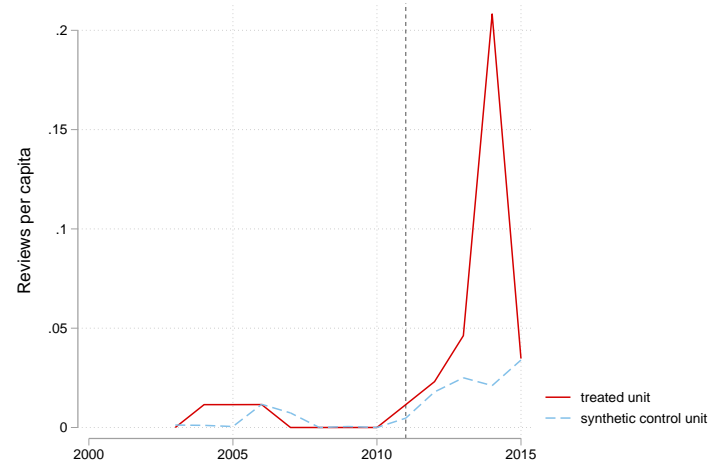

Figure B.7: Synthetic Control Results for Midland, TX (Midland)

Gonorrhea Rate

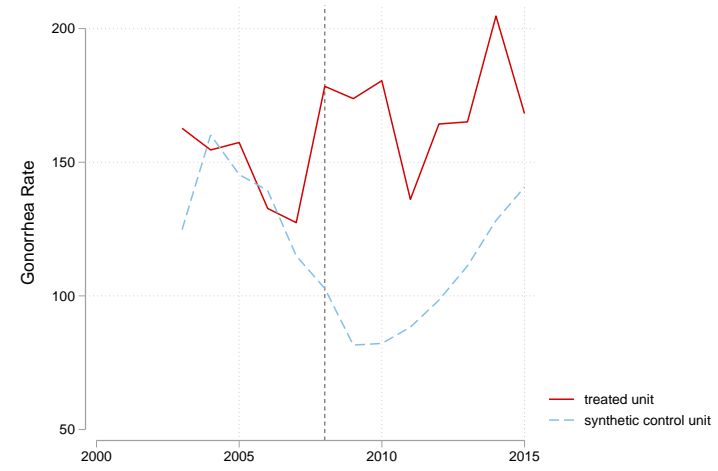

Reviews per capita

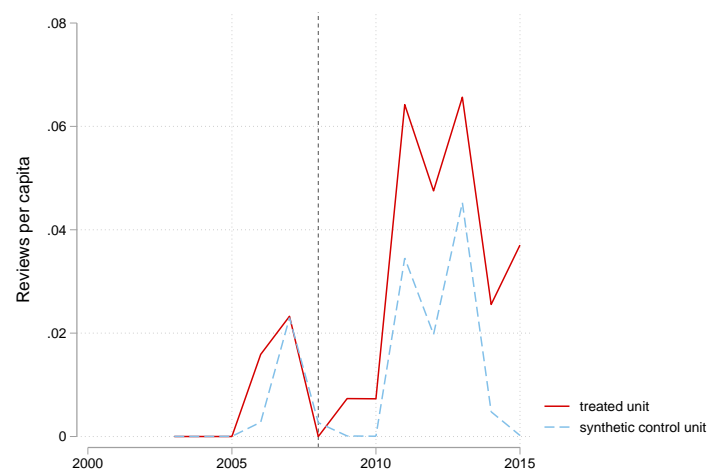


Figure B.8: Synthetic Control Results for Ector, TX (Odessa)

Gonorrhea Rate

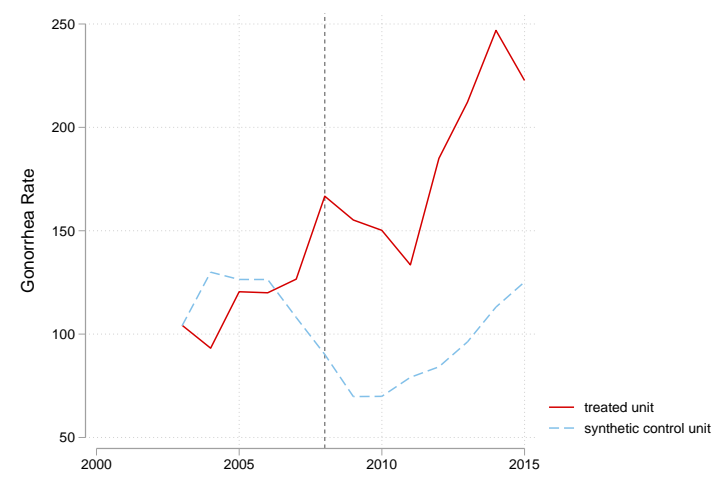

Reviews per capita

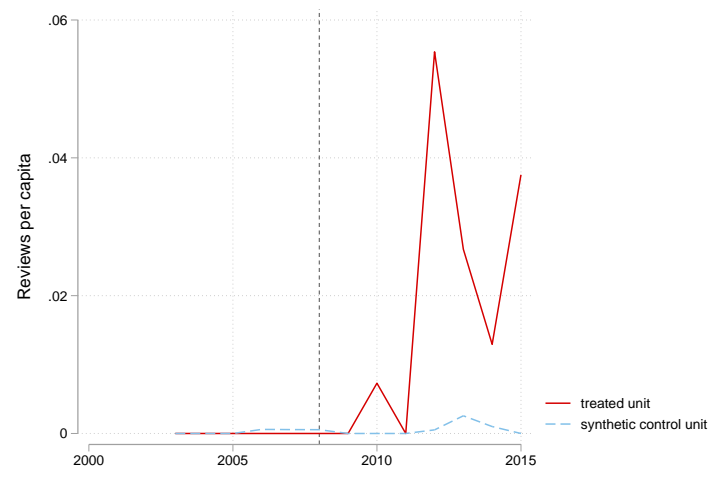

Figure B.9: Synthetic Control Results for Webb, TX (Laredo)

Gonorrhea Rate

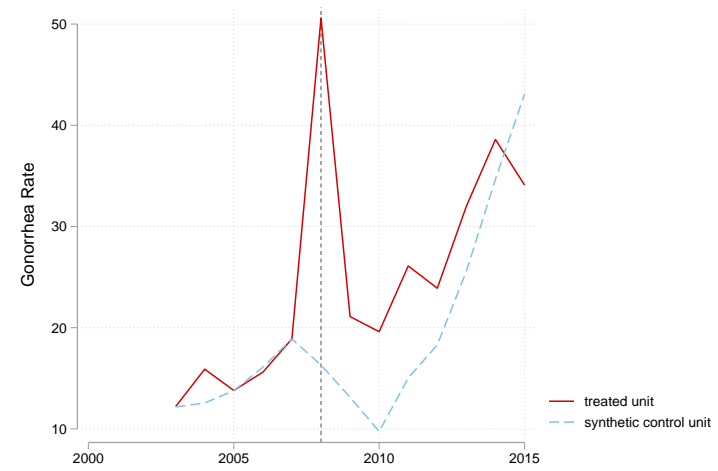

Reviews per capita

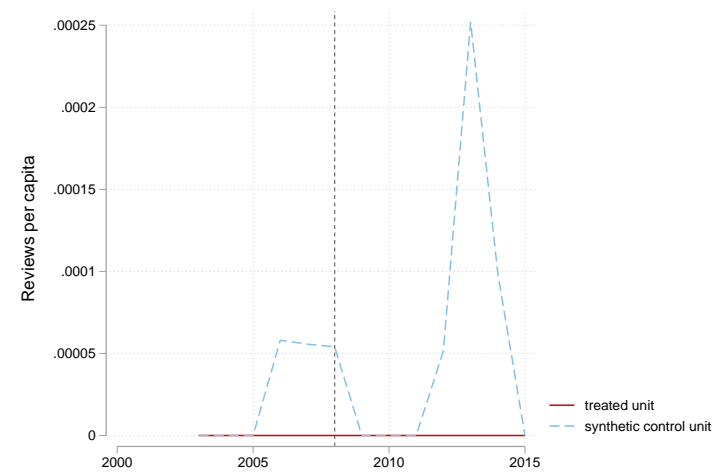

Figure B.10: Synthetic Control Results for Lea, NM (Hobbs)

Gonorrhea Rate

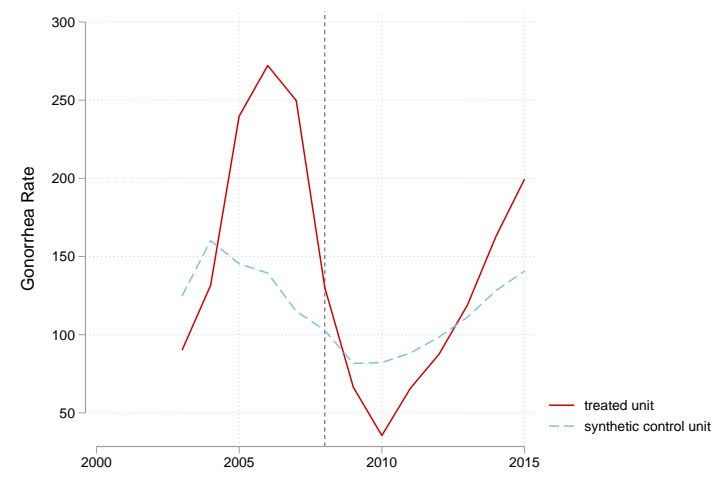

Reviews per capita

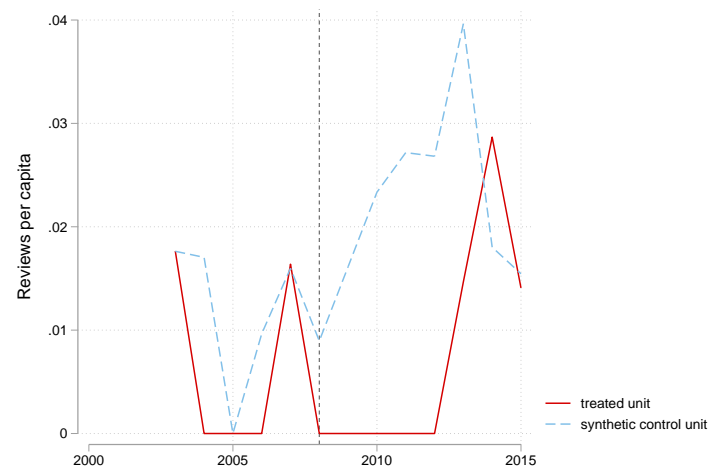


Figure B.11: Synthetic Control Results for Natrona, WY (Casper)

Gonorrhea Rate

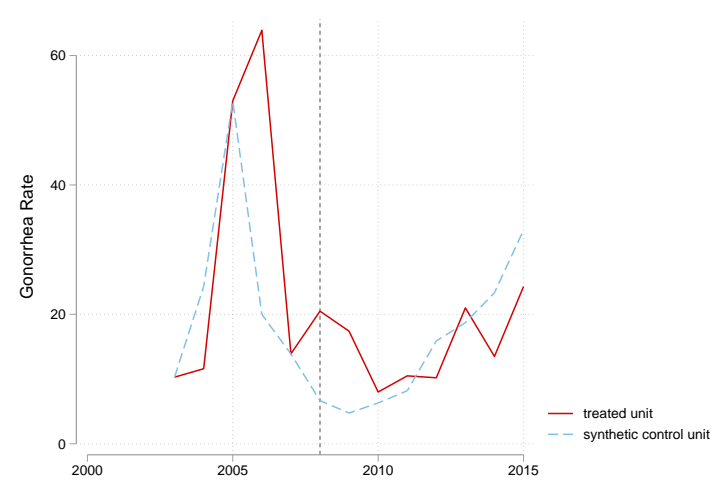

Reviews per capita

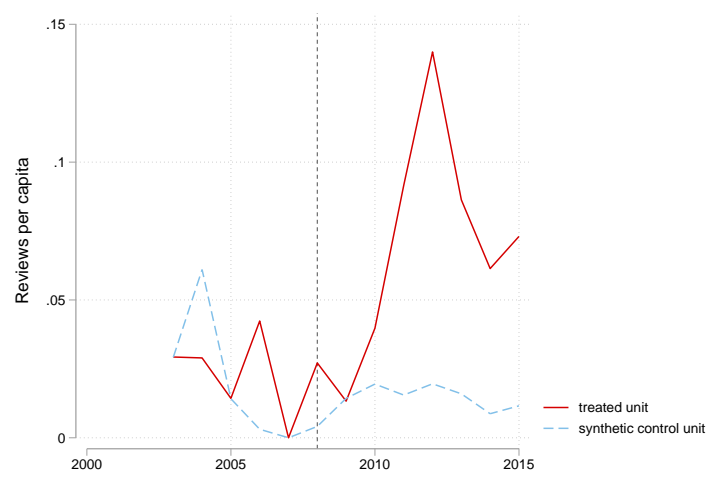

